\title{
Anatomical Characterization of a Rabbit Cerebellar Eyeblink Premotor Pathway Using Pseudorabies and Identification of a Local Modulatory Network in Anterior Interpositus
}

\author{
Jimena Gonzalez-Joekes ${ }^{1,2}$ and Bernard G. Schreurs ${ }^{1,3}$ \\ ${ }^{1}$ Blanchette Rockefeller Neurosciences Institute, and Departments of ${ }^{2}$ Neurobiology and Anatomy, and ${ }^{3}$ Physiology and Pharmacology, West Virginia \\ University, Morgantown, West Virginia 26506
}

\begin{abstract}
Rabbit eyeblink conditioning is a well characterized model of associative learning. To identify specific neurons that are part of the eyeblink premotor pathway, a retrograde transsynaptic tracer (pseudorabies virus) was injected into the orbicularis oculi muscle. Four time points $(3,4,4.5$, and $5 \mathrm{~d})$ were selected to identify sequential segments of the pathway and a map of labeled structures was generated. At $3 \mathrm{~d}$, labeled first-order motor neurons were found in dorsolateral facial nucleus ipsilaterally. At $4 \mathrm{~d}$, second-order premotor neurons were found in reticular nuclei, and sensory trigeminal, auditory, vestibular, and motor structures, including contralateral red nucleus. At $4.5 \mathrm{~d}$, labeled third-order premotor neurons were found in the pons, midbrain, and cerebellum, including dorsolateral anterior interpositus nucleus and rostral fastigial nucleus. At $5 \mathrm{~d}$, labeling revealed higher-order premotor structures. Labeled fourth-order Purkinje cells were found in ipsilateral cerebellar cortex in cerebellar lobule HVI and in lobule I. The former has been implicated in eyeblink conditioning and the latter in vestibular control. Labeled neurons in anterior interpositus were studied, using neurotransmitter immunoreactivity to classify individual cell types and delineate their interconnectivity. Labeled third-order premotor neurons were immunoreactive for glutamate and corresponded to large excitatory projection neurons. Labeled fourth-order premotor interneurons were immunoreactive for GABA (30\%), glycine (18\%), or both GABA and glycine (52\%) and form a functional network within anterior interpositus involved in modulation of motor commands. These results identify a complete eyeblink premotor pathway, deep cerebellar interconnectivity, and specific neurons responsible for the generation of eyeblink responses.
\end{abstract}

\section{Introduction}

Delay eyeblink conditioning is a well characterized model of associative learning but the locus of learning is still a matter of debate. Possible sites of plasticity have been found in the anterior interpositus nucleus (AIN) of the deep cerebellar nuclei (DCN) (McCormick et al., 1982; Marek et al., 1984; Nowak and Gormezano, 1990; Thompson and Steinmetz, 2009; Freeman and Steinmetz, 2011), lobule HVI of the cerebellar cortex (Yeo et al., 1985; Gould and Steinmetz, 1996; Schreurs et al., 1998; Jirenhed et al., 2007; Kellett et al., 2010), and anterior lobule (Perrett and Mauk, 1995; Green and Steinmetz, 2005). Identification of a complete cerebellar premotor pathway of the eyeblink response can be of great value in elucidating the specific components in-

Received May 1, 2012; revised June 18, 2012; accepted July 16, 2012.

Author contributions: J.G.-J. and B.G.S. designed research; J.G.-J. performed research; J.G.-J. analyzed data; J.G.-J. and B.G.S. wrote the paper.

This research was supported in part by NHH Grant NS061103, a WVU Bridge Grant, and funds from Blanchette Rockefeller Neurosciences Institute. PRV strains were provided by L.W. Enquist supported by NIH P40 OD010996. We thank Carrie Smith-Bell and Roger Bell for technical assistance.

The authors declare no competing financial interests.

Correspondence should be addressed to either of the following: Jimena Gonzalez-Joekes, Blanchette Rockefeller Neurosciences Institute, 8 Medical Center Drive, West Virginia University, Morgantown, WV 26506, E-mail: jgonzalez@hsc.wvu.edu; or Bernard G. Schreurs, Blanchette Rockefeller Neurosciences Institute, 8 Medical Center Drive, West Virginia University, Morgantown, WV 26506, E-mail: bschreurs@hsc.wvu.edu.

DOI:10.1523/JNEUROSCI.2088-12.2012

Copyright $\odot 2012$ the authors $\quad 0270-6474 / 12 / 3212472-16 \$ 15.00 / 0$ volved in the generation and modulation of eyeblink conditioning.

DCN is the final filter that integrates all the information processed in the cerebellum and generates its sole output. However, unlike the cerebellar cortex, the circuitry of the DCN is poorly understood. There are at least six types of neurons in the DCN, including large glutamatergic projection neurons, two types of inhibitory projection neurons, and at least two types of interneurons. The only excitatory output of the DCN is generated by large glutamatergic neurons that project to different extra-cerebellar sites and comprise $\sim 50 \%$ of the total DCN neuronal population (Batini et al., 1992; Teune et al., 2000). The first type of inhibitory projection neuron is a small GABAergic neuron that projects to the inferior olive and forms the nucleo-olivary feedback loop (Tolbert et al., 1976; de Zeeuw et al., 1989). The second type is a large glycinergic neuron (recently discovered in the fastigial nucleus) that projects to vestibular and reticular sites (Bagnall et al., 2009). Recent electrophysiological studies in transgenic mice expressing GAD-eGFP or GlyT2-eGFP were able to distinguish at least two types of interneurons: a GABAergic or mixed GABA/ glycinergic interneuron and a non-GABAergic (possibly glutamatergic) interneuron (Uusisaari and Knöpfel, 2010, 2011). However, the role of these interneurons is unknown and their interactions have not been studied.

Retrograde transsynaptic viral tracers are a powerful tool for identifying neuronal networks. Attenuated pseudorabies virus 


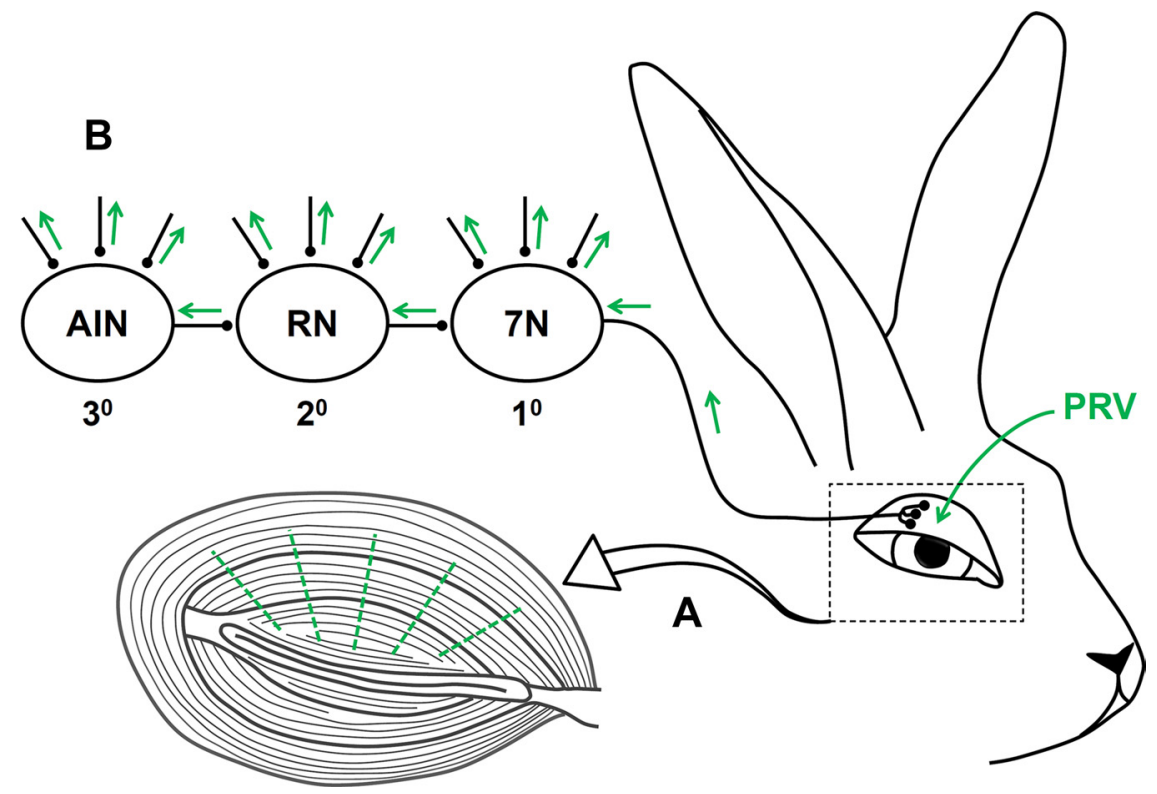

Figure 1. Schematic diagram of the $00 \mathrm{M}$ premotor pathway labeled with PRV. $A$ shows the location of 5 PRV injections (green dashed lines) in 00M that include the orbital, preseptal, and pretarsal muscles. $\boldsymbol{B}$ shows the retrograde transsynaptic spread of PRV through the $00 \mathrm{M}$ premotor pathway. Directional and sequential spread of PRV through first-order $\left(1^{\circ}\right)$ motor neurons in the facial nucleus $(7 \mathrm{~N})$, second-order $\left(2^{\circ}\right)$ premotor neurons in the red nucleus (RN) and other areas, and third-order $\left(3^{\circ}\right)$ premotor neurons in the AIN of the cerebellum and other areas.

Bartha (PRV) (Bartha, 1961) reveals that hierarchical chains of functionally connected neurons and multisynaptic pathways can be identified by following the extent and time course of the PRV infection (Daniels et al., 1999; Billig et al., 2000; Kerman et al., 2006; Van Daele and Cassell, 2009). In the present study, the premotor pathway of the rabbit orbicularis oculi muscle (OOM) responsible for the eyeblink was traced retrogradely using PRV. Neurons in the AIN involved in the pathway were characterized based on their neurotransmitter content. Of particular importance, three different types of inhibitory interneurons that are part of the OOM premotor pathway were revealed to form a possible functional network within the AIN for the modulation of motor commands.

\section{Materials and Methods}

Animals

Twenty-four adult male New Zealand rabbits (Oryctolagus cuniculus), between 3 and 4 months of age, weighing $\sim 2.5 \mathrm{~kg}$, were supplied by Harlan. Four rabbits were assigned to each of four different time points for PRV anatomical tracing ( $3 \mathrm{~d}, 4 \mathrm{~d}, 4.5 \mathrm{~d}$, and $5 \mathrm{~d}$ ) and four rabbits were assigned to each of two time points for neurotransmitter immunohistochemistry ( $4.5 \mathrm{~d}$ and $5 \mathrm{~d}$ ). Rabbits were housed in individual cages, given ad libitum access to food and water, and maintained on a $12 \mathrm{~h}$ light/dark cycle, all in accordance with the National Institute of Health guidelines. All procedures were approved by the West Virginia University Animal Care and Use Committee.

\section{$P R V$ injections}

An attenuated PRV expressing an enhanced green fluorescent protein (PRV-152) was used as a retrograde transsynaptic tracer (Smith et al., 2000). The PRV was a kind gift from L. W. Enquist (Princeton University, Princeton, NJ). PRV enters the neuron terminals by fusion. Once inside, the virus caspids interact with the neuron's dynein, a cellular microtubule-associated motor protein, and it travels retrogradely to the nucleus where it replicates. After replication, it moves to the dendrites where it infects synaptically connected cells (Curanović et al., 2009; Curanovic and Enquist, 2009). PRV does not label sensory pathways, and even though it can be taken up by sensory neurons, its exclusively retro- grade properties confine the virus to the sensory neuron soma and it does not spread any further (Smith et al., 2000; Mettenleiter, 2002; Mettenleiter et al., 2006). The same batch of PRV was used for all injections at a concentration of $2.3 \times 10^{8}$ plaque-forming units per milliliter $(\mathrm{PFU} / \mathrm{ml})$. After arrival, PRV was aliquoted and stored at $-80^{\circ} \mathrm{C}$. Before PRV injections, rabbits were anesthetized with $20 \mathrm{mg} / \mathrm{kg}$ Ketamine and $4 \mathrm{mg} / \mathrm{kg}$ Xylazine. Their right eyelid was shaved and cleaned with isopropyl alcohol. After thawing, PRV was sonicated for $2 \mathrm{~min}$. A glass, $10 \mu \mathrm{l}$ Hamilton syringe with a 31 -gauge needle was rinsed three times in $95 \%$ ethanol, sterile $\mathrm{dH}_{2} \mathrm{O}$, sterile saline, and PRV. Fifteen microliters of PRV divided into 5 injections of $3 \mu \mathrm{l}$ each were injected into the right OOM. Each injection was transverse to the muscle fibers and delivered at a constant rate through the orbital, preseptal, and pretarsal portions of the OOM to ensure adequate viral distribution. After injection, the syringe was left in place for $10 \mathrm{~min}$ to achieve complete viral absorption and to prevent any leakage. A basic diagram of the PRV procedures is depicted in Figure 1.

\section{Tissue processing}

The 16 rabbits used for the delineation of the OOM premotor pathway were injected with Euthasol (sodium pentobarbital, $390 \mathrm{mg} / \mathrm{ml}$ ) and exsanguinated with $1.0 \mathrm{cc}$ Euthasol (sodium pentobarbital, 390 $\mathrm{mg} / \mathrm{ml})$ at $3(n=4), 4(n=4), 41 / 2(n=4)$, or $5(n=4) \mathrm{d}$ after PRV-injections. They were perfused transcardially with 1.51 of $0.9 \%$ saline ( $\mathrm{pH} 7.4$ at room temperature) followed by 11 of $4 \%$ formaldehyde. For anti-PRV immunohistochemistry, brains were collected and placed in fixative for $4 \mathrm{~h}$ and transferred to $30 \%$ sucrose for cryoprotection until they sank and $50 \mu \mathrm{m}$ sections were cut on a freezing microtome.

Eight rabbits were used for characterization of AIN neurons based on their neurotransmitter immunoreactivity. Animals were injected with Euthasol (sodium pentobarbital, $390 \mathrm{mg} / \mathrm{ml}$ ) and exsanguinated with 1.0 cc Euthasol (sodium pentobarbital, $390 \mathrm{mg} / \mathrm{ml})$ at $4.5(n=4)$ or $5(n=$ 4) d after PRV-injections. They were perfused transcardially with 1.51 of $0.9 \%$ saline ( $\mathrm{pH} 7.4$ at room temperature) followed by 11 of $2.5 \%$ glutaraldehyde and $1.5 \%$ formaldehyde. Brains were placed in fixative for $6 \mathrm{~h}$, transferred to $30 \%$ sucrose for cryoprotection until they sank, and 25 $\mu \mathrm{m}$ sections were cut. All sections were marked on the contralateral side of injection to distinguish laterality.

\section{Anti-PRV immunohistochemistry}

Free-floating sections were washed in $0.5 \mathrm{M}$ Tris and placed in $3 \% \mathrm{H}_{2} \mathrm{O}_{2}$ for $30 \mathrm{~min}$ to quench endogenous peroxidases. Antigen retrieval was accomplished by incubating the sections in citrate buffer, $\mathrm{pH} 3.0$, for 30 min at $37^{\circ} \mathrm{C}$. After washing, the sections were blocked for $1 \mathrm{~h}$ in $3 \%$ normal rabbit serum and incubated in a goat anti-PRV primary antibody overnight at $4^{\circ} \mathrm{C}$ ( polyclonal gb-320 developed by R. Miselis, Philadelphia, PA, 1:10,000). The PRV primary antibody has been described extensively (Chen et al., 1999; Aston-Jones and Card, 2000; Aston-Jones et al., 2004; James et al., 2008). After washing, the sections were placed in a secondary antibody (biotinylated rabbit anti-goat 1:200) for $1 \mathrm{~h}$. The sections were then washed and placed in ABC (Vector Kit, Vector Labs) for $1 \mathrm{~h}$, washed once more, and stained with DAB (Vector Kit, Vector Labs) for 2-4 min until color developed.

The location of each PRV-labeled neuron was plotted on sequential coronal sections of the rabbit brain but a specific structure was only considered to be labeled and reported here if more than one neuron was labeled in that structure in each of the four rabbits used for a given time point. 


\section{Fluorescence}

neurotransmitter immunoreactivity

The $25 \mu \mathrm{m}$ free floating sections were treated with $0.5 \%$ sodium borohydride in $0.1 \mathrm{M}$ PBS, pH. 7.2, for $30 \mathrm{~min}$ to quench autofluorescence produced by glutaraldehyde, and followed by repeated washes. Sections containing the DCN were incubated with primary antibodies for $72 \mathrm{~h}$ and with secondary antibodies for $48 \mathrm{~h}$ at $4^{\circ} \mathrm{C}$ in a buffer solution containing $0.1 \mathrm{M} \mathrm{PBS}$, $\mathrm{pH} 7.2,3 \%$ normal goat serum, and $0.1 \%$ sodium azide (preservative). After specificity tests, an optimal immunolabeling protocol was developed. First, sections were incubated in a polyclonal goat anti-PRV (gb-320 1:10,000) followed by its secondary antibody (donkey anti-goat Alexa 488, Invitrogen; 1:500). Second, sections were incubated in a mixture of monoclonal mouse anti-L-glutamate conjugated to glutaraldehyde and bovine serum albumin (anti-Glu-G-BSA; Millipore MAB5304, $1: 1000$ ), polyclonal guinea pig anti-GABA conjugated to glutaraldehyde and keyhole limpet hemocyanin (anti-GABA-G-KLH; Millipore $\mathrm{AB} 175,1: 1000)$, and polyclonal rabbit antiglycine conjugated to glutaraldehyde and BSA (anti-Gly-G-BSA; Millipore AB139, 1:1000). After primary antisera incubation, sections were washed several times over $24 \mathrm{~h}$ with $0.1 \mathrm{M}$ PBS and $0.1 \%$ sodium azide. Sections were then incubated with secondary antibodies (goat anti-rabbit Alexa 405, goat anti-mouse Alexa 546, and goat anti-guinea pig Alexa 633; Invitrogen, 1:400). The sections were then washed and mounted on gelatin-covered mounting slides and coverslipped using Fluoromount-G mounting media (SouthernBiotech) and \#1.5 coverslips (Fisher Scientific).

\section{Antibody characterization}

Monoclonal mouse anti-glutamate antiserum (Millipore, MAB5304) has been previously characterized in several studies (Chagnaud et al., 1989; Roche et al., 2003; Wu et al., 2005). Specificity testing by competition experiments using ELISA performed by the manufacturer showed no cross-reactivity with aspartate-GBSA, GABA-G-BSA, or Gly-G-BSA.

Polyclonal guinea pig anti-GABA antiserum (Millipore, AB175) has been used to identify GABAergic neurons by light and electron microscopy (manufacturer's technical information) and tested in dot blots showing specificity for its conjugated antigen, and immunoreactivity can be removed by preabsorption with its antigen (Chalazonitis et al., 2008). In addition, antiGABA-G-KLH has been extensively characterized in different preparations and species (McDonald and Pearson, 1989; Roettger et al., 1989; Dmitrieva et al., 2001; Rubio and Juiz, 2004; Stanić et al., 2010).

The polyclonal rabbit anti-glycine antiserum (Millipore, AB139) has been used in different tissue preparations and species (Avendaño et al., 2005; Fredrich et al., 2009; Kuo et al., 2009; Downie et al., 2010). Specificity testing by competition experiments using ELISA performed by the manufacturer showed no cross-reactivity with GABA-G-BSA, Glu-G-BSA, taurine-GBSA, or aspartate-G-BSA. The specificity of this antiserum was also tested by Western blotting in sea lamprey brain homogenates and showed high specificity for Gly-G-BSA (Villar-Cerviño et al., 2006).

Controls and specificity tests

In the present study, additional neurotransmitter antisera specificity tests were performed. First, omission controls in which the primary antibodies were replaced with incubating buffer eliminated immunoreactivity.

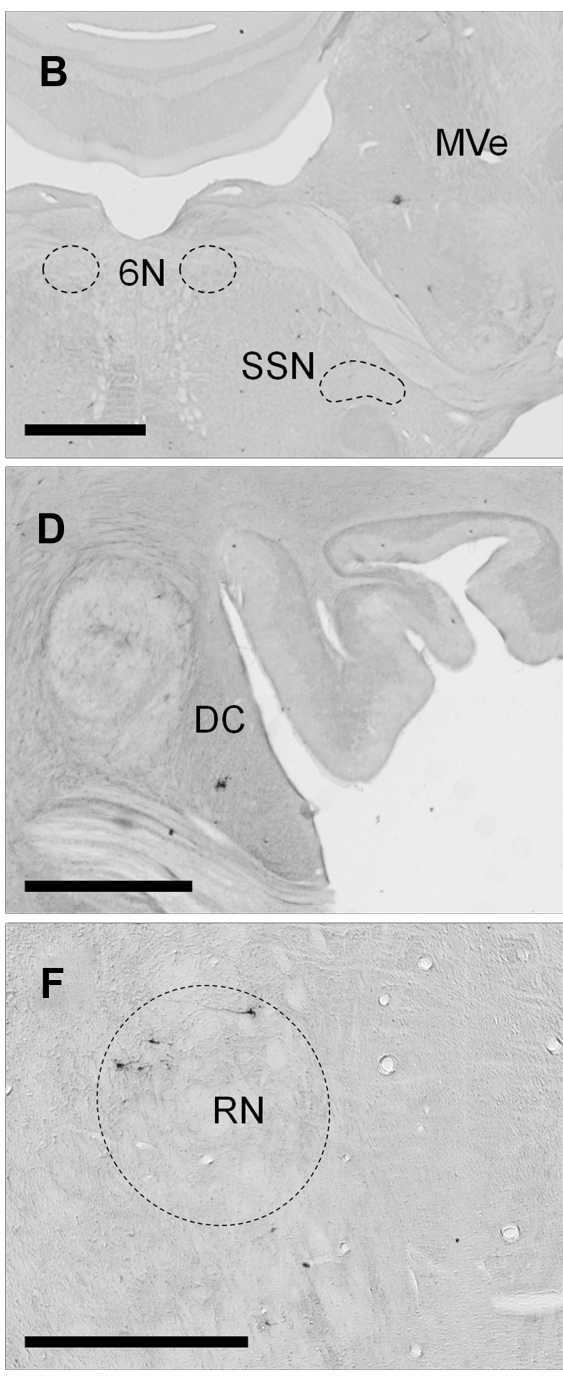

Figure 2. Examples of PRV-labeled neurons in the rabbit brain 3 and $4 \mathrm{~d}$ after injection. $A$, PRV-labeled first-order motor neurons are located in the dorsolateral facial nucleus ipsilaterally $3 \mathrm{~d}$ after PRV injection into the right $00 \mathrm{M}$. DL, Dorsolateral; $\mathrm{L}$, lateral; Int, intermediate; $\mathrm{M}$, medial; VM, ventromedial subnuclei. $\boldsymbol{B}-\boldsymbol{F}$, PRV-labeled neurons $4 \mathrm{~d}$ after PRV injection. $\boldsymbol{B}$ shows nucleus (SSN) and abducens nucleus (6N). C shows PRV labeling in the ventral spinal trigeminal nucleus, oral part (Sp50) ipsilatD. Discrete PRV labeling in the rostral dorsal cochlear nucleus (DC) ipsilaterally. $\boldsymbol{E}$ shows PRV-labeled neurons in the parabrachial nucleus (PB) and Kölliker-fuse nucleus (KF) ipsilaterally. $F$ shows PRV-labeled neurons in the dorsolateral red nucleus (RN) contralaterally. Scale bars: $1 \mathrm{~mm}$.

Second, preabsorption of the primary antibodies with the immunizing peptide (purchased from Invitrogen or Vector Labs) also eliminated immunoreactivity. Third, preabsorption of each primary antibody with the other two conjugated peptides did not reduce immunoreactivity (e.g., $5 \mu \mathrm{l}$ of anti-GABA-G-BSA preabsorbed with $1 \mu \mathrm{l}$ of glycine-G-BSA and $1 \mu \mathrm{l}$ of glutamate-G-BSA did not reduce immunoreactivity for GABA; the same was true for the other two conjugated antibodies). In addition, identical immunoreactivity was seen in experiments where the three preabsorbed primary antibodies were used sequentially compared with experiments where primary antibodies were used simultaneously. All control tests were performed on the cerebellar cortex where the neurotransmitter profile of cells has been well characterized and where granule cells are exclusively glutamatergic, stellate and basket cells are GABAergic, globular cells are glycinergic, and Golgi cells are both GABAergic and glycinergic (Ottersen et al., 1988; Simat et al., 2007).

\section{Image acquisition}

Light microscopy. Images were acquired using an upright Olympus AX70 light microscope with a motorized stage and with $4 \times($ NA 0.15$)$ or $10 \times$ (NA 0.4) objectives. Some pictures of different brain structures were 
Table 1. Labeled areas after PRV injection into the right 00M

\begin{tabular}{|c|c|c|c|}
\hline \multicolumn{4}{|c|}{ Days after PRV injection } \\
\hline $3 d(n=4)$ & $4 \mathrm{~d}(n=4)$ & $4.5 \mathrm{~d}(n=4)$ & $5 d(n=4)$ \\
\hline Facial Nucleus ${ }^{\text {(Ipsi) }}$ & 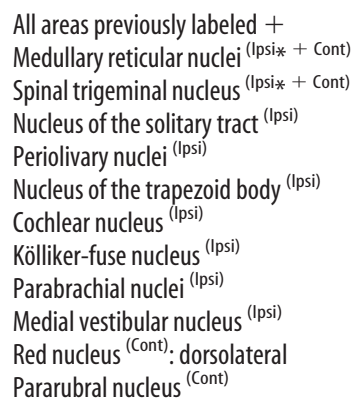 & 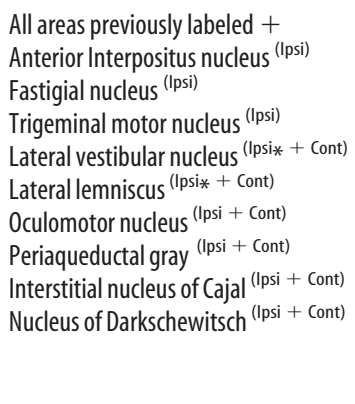 & 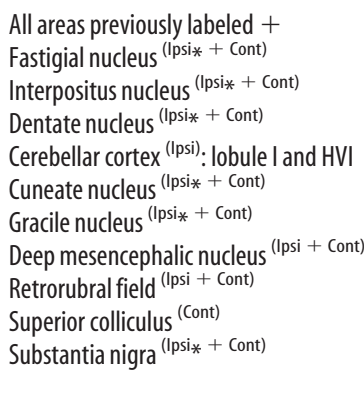 \\
\hline
\end{tabular}

Ipsi, Ipsilateral; Cont, contralateral; $\left(^{*}\right)$ predominant.

acquired using the virtual slice module to produce high resolution images (West Virginia University, Microscopic Imaging Facility).

Confocal microscopy. Neurotransmitter immunofluorescent reactivity of the DCN of rabbits previously injected with PRV (4.5 and $5 \mathrm{~d}$ ) was visualized using a confocal laser scanning microscope (Zeiss LSM 710; Carl Zeiss International). Images were acquired using 405, 488, 514, and $633 \mathrm{~nm}$ lasers, sequential multichannel line scan, averaged twice, pinhole aperture of $1 \mathrm{AU}, 1024 \times 1024$ resolution, and the filters were set manually to detect the spectral peak of each fluorophore. All coronal sections $(25 \mu \mathrm{m})$ of the DCN were visualized first using a $10 \times$ objective (NA 0.4) to locate all PRV-labeled neurons. Only PRV-labeled neurons with a visible nucleus were included in this study to standardize data acquisition and to avoid over counting. Classification of DCN cell neurotransmitter immunoreactivity was performed using a $63 \times$ oil-immersion objective (NA 1.4). Images were exported to Adobe Photoshop 8.0 and only minor adjustments of brightness and contrast were made.

\section{Results}

The directional and temporal pattern of PRV retrograde spread through synaptically connected circuits can be used to identify specific pathways. In the present study, four different time points were used to identify each step in the rabbit OOM premotor pathway. Based on pilot data, four time points were selected to best represent the progression of PRV labeling through each step in the pathway ( $3 \mathrm{~d}, n=4 ; 4 \mathrm{~d}, n=4 ; 4.5 \mathrm{~d}, n=4$; and $5 \mathrm{~d}$, $n=4)$.

\section{Mapping the OOM premotor pathway}

Three days after PRV injections in the OOM, first-order motor neurons labeled with PRV were seen in the ipsilateral facial nucleus (Fig. $2 \mathrm{~A}$ ). Labeled neurons were located in the dorsolateral and dorsal portions of the intermediate and lateral subdivisions of the nucleus, forming a cap-like distribution in agreement with the location of motor neurons innervating the OOM found in previous studies (Radpour, 1977; Komiyama et al., 1984; Klein et al., 1990; VanderWerf et al., 1998; Horta-Júnior et al., 2004; McNeal et al., 2008). Importantly, the same region of the nucleus was labeled in all rabbits. Exclusive PRV uptake by OOM motor neurons was corroborated by examination of motor and preautonomic structures known to innervate other ocular muscles and glands. The abducens nucleus that innervates extraocular muscles was not labeled with PRV at any of the time points examined (Fig. 2B). In addition, the superior lacrimal and salivatory nucleus, which contains preganglionic autonomic efferents to the eyelid glands and smooth muscle, was also not labeled with PRV in any of the subjects used in this study at any of the time points (Fig. $2 B$ ). The facial nucleus and other structures labeled with PRV at 3, 4, 4.5, and $5 \mathrm{~d}$ are shown in Table 1.
Four days after PRV injection, premotor structures were labeled. A group composite of PRV-labeled neurons was plotted in a map of coronal sections (Fig. 3) to best represent the distribution of labeled neurons at this time. PRV-labeled neurons were found in the dorsal, intermediate, and ventral medullary reticular nucleus predominately ipsilaterally but some were seen on the contralateral side. In addition, labeled neurons were found in the magnocellular, gigantocellular, lateral paragigantocellular, parvicellular, and lateral reticular nucleus mostly ipsilaterally. Vestibular second-order labeled neurons at this time were seen only in the ventral part of the medial vestibular nucleus ipsilaterally (Fig. $2 \mathrm{~B})$. In addition, labeled neurons were found in the medial and ventral portions of the caudal, interpolar, and oral spinal trigeminal nucleus and in the ventral part of the principal sensory trigeminal nucleus exclusively on the ipsilateral side, in agreement with the location of spinal and principal sensory trigeminal neurons that have been shown to make monosynaptic connections to the facial motor nucleus and generate reflex eyeblink responses (Hinrichsen and Watson, 1983; Yokota et al., 1991; van Ham and Yeo, 1996a, 1996b; Henriquez and Evinger, 2007). Figure $2 C$ depicts a characteristic neuron located in the ventral spinal trigeminal nucleus (oral part). Second-order auditory areas including the nucleus of the trapezoid body, periolivary nuclei, and dorsal cochlear nucleus were labeled ipsilaterally at this time. Labeling of the trapezoid body was confined to the dorsolateral region. A few labeled neurons were seen in the medial and lateral periolivary nuclei. The rostral portion of the dorsal cochlear nucleus was also labeled with PRV on the ipsilateral side at this time (Fig. 2D). A discrete group of labeled neurons were found in the Köllikerfuse nucleus and the ventral part of the medial parabrachial nucleus on the ipsilateral side (Fig. 2E). The Kölliker-fuse and the parabrachial nucleus are involved in the modulation of breathing and may play a role in synchronizing OOM activity and respiration (Chamberlin and Saper, 1994; Bonis et al., 2010; Song et al., 2012). Finally at this time point, labeled neurons were seen in the dorsolateral red nucleus on the contralateral side (Fig. 2 F). These neurons were located in the caudal portion of the magnocellular red nucleus, a region that has been shown to innervate the OOM portion of the facial nucleus and generates blink responses when stimulated (Takada et al., 1984; Daniel et al., 1987; Chapman et al., 1988; Holstege and Tan, 1988). In addition, a small number of labeled neurons were found in the adjacent contralateral pararubral nucleus.

Examples of PRV-labeled premotor neurons $4.5 \mathrm{~d}$ after PRV injection and a group composite are depicted in Figures 4 and 5, respectively. An increase in labeling was seen at this time and 


\section{caudal}

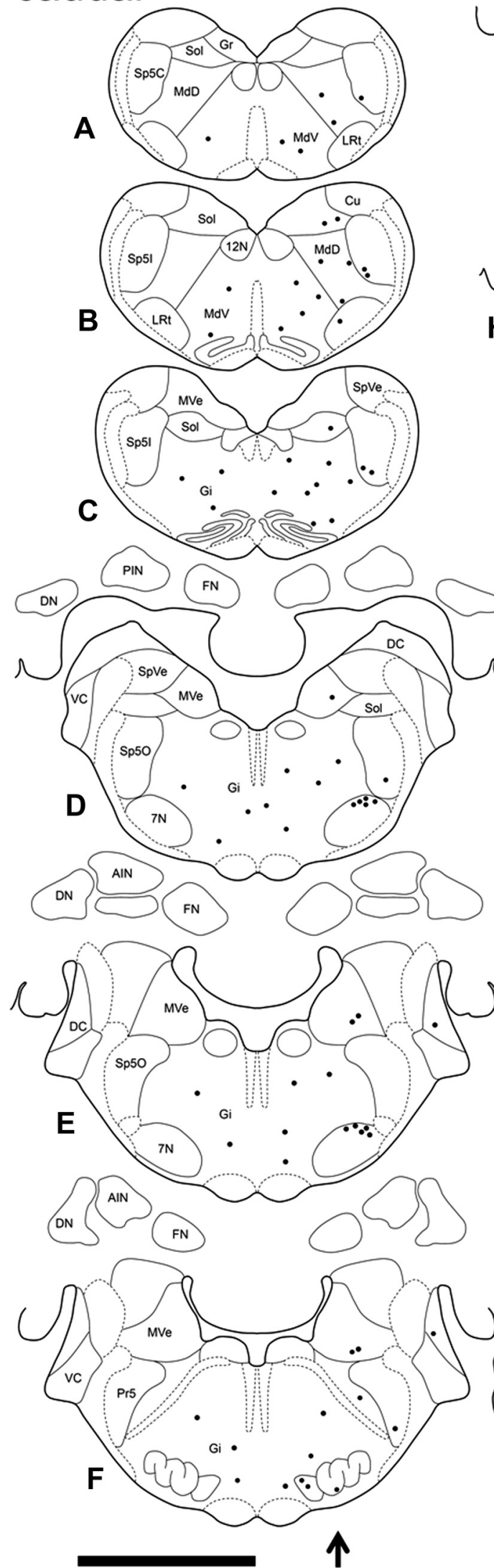

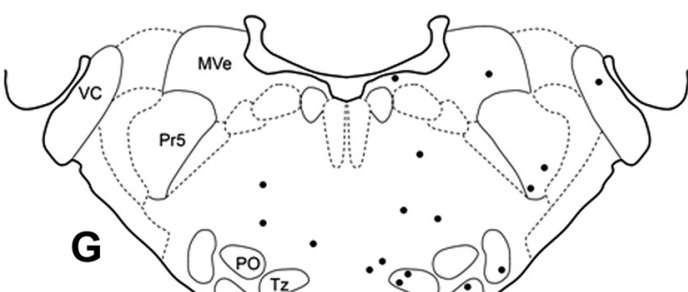
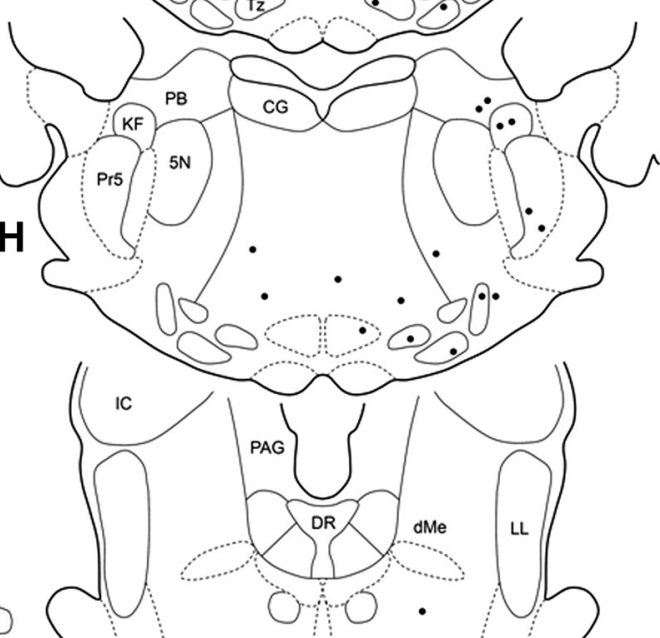
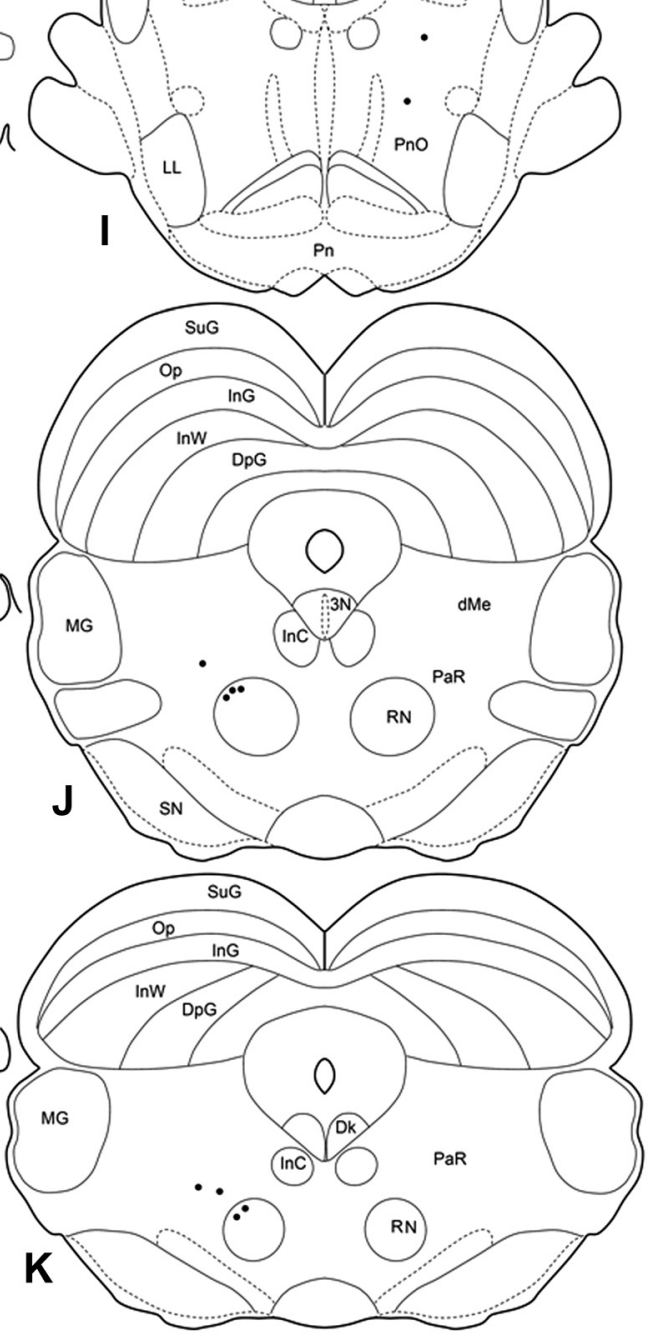

rostral

Figure 3. Distribution of PRV-labeled neurons in the brain $4 \mathrm{~d}$ after PRV injection in the right $00 \mathrm{M}$. A composite of the location of PRV-labeled neurons found across four animals plotted in sequential sections to best represent the pattern of PRV labeling. Sections are arranged caudorostrally $(\boldsymbol{A}-\boldsymbol{K})$. The arrow indicates the side of PRV injection. Each dot represents one PRV-labeled neuron. 3N, Oculomotor nucleus; 4N, trochlear nucleus; $5 \mathrm{~N}$, motor trigeminal nucleus; 7N, motor facial nucleus; 12N, hypoglossal nucleus; AIN, anterior interpositus; (G, central (Figure legend continues.) 


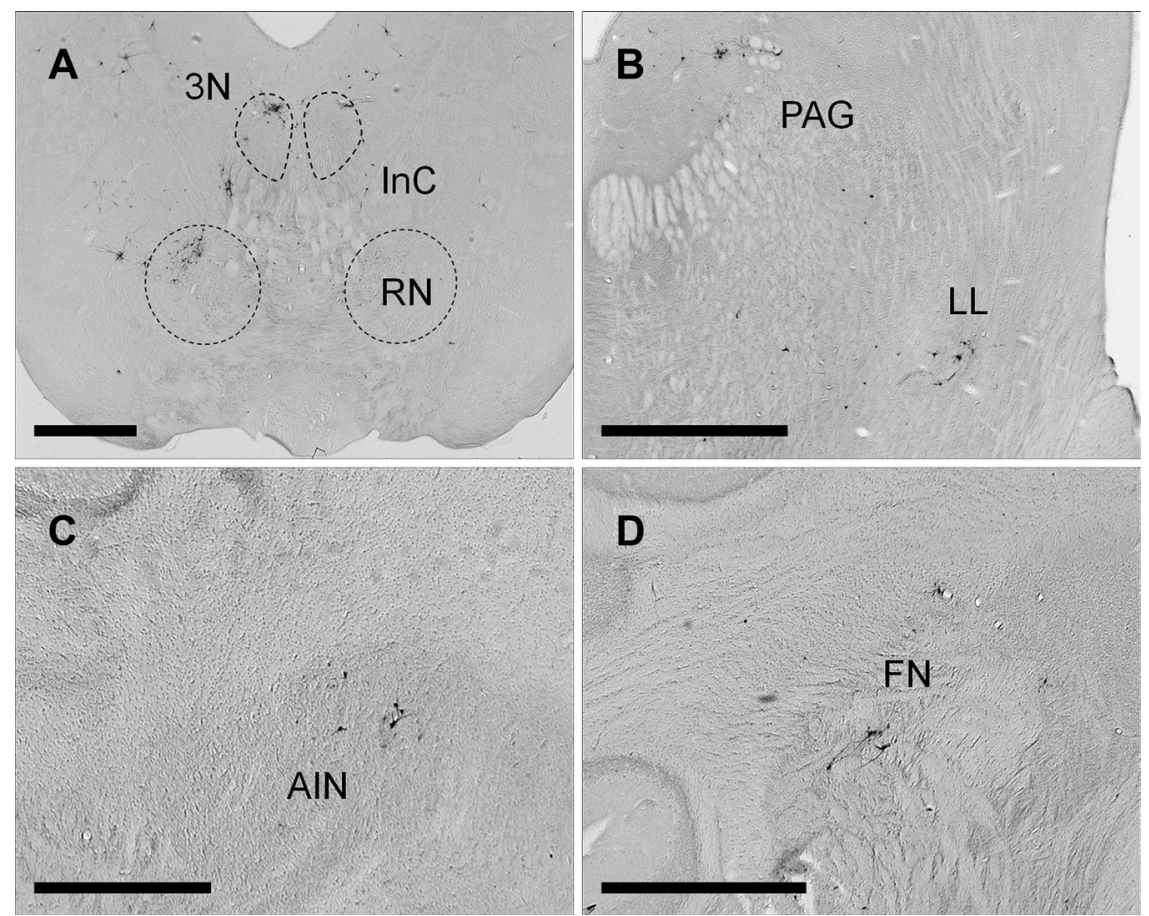

Figure 4. $\quad \boldsymbol{A}-\boldsymbol{D}$, Examples of PRV-labeled premotor neurons $4.5 \mathrm{~d}$ after injection. $\boldsymbol{A}$ shows PRV-labeled neurons in the dorsolateral red nucleus (RN) and pararubral nucleus contralaterally. The oculomotor nucleus (3N), interstitial nucleus of (ajal (InC), and supraoculomotor periaqueductal gray are labeled bilaterally. $\boldsymbol{B}$ shows PRV-labeled neurons in the lateral lemniscus (LL) and periaqueductal gray (PAG) ipsilaterally. C shows a few PRV-labeled neurons in the dorsolateral AIN ipsilaterally. D shows PRVlabeled neurons in the rostral fastigial nucleus (FN) ipsilaterally. Scale bars: $1 \mathrm{~mm}$.

higher-order structures that comprise third-order neurons were revealed. Labeled neurons in the medullary and reticular nuclei became more numerous bilaterally. The nucleus of the trapezoid body and the medial and lateral periolivary nuclei showed an increase in labeling that remained mostly ipsilateral. In addition, PRV-labeled neurons were seen in the medial ventral periolivary nucleus. The spinal and principal sensory trigeminal nucleus showed an increase in labeling, and a few labeled neurons were seen on the contralateral side. A few labeled neurons were found in the ipsilateral motor trigeminal nucleus. The dorsal cochlear nucleus was labeled bilaterally and also some labeled neurons were seen in the ventral cochlear nucleus ipsilaterally. The parabrachial and Kölliker-fuse nucleus showed a small increase in labeling and only a few neurons were seen on the contralateral side. Labeling in the medial vestibular nucleus became more dense and bilateral. In addition, PRV-labeled neurons were

$\leftarrow$

(Figure legend continued.) gray; Cn, cuneiform nucleus; DC, dorsal cochlear; Dk, nucleus of Darkschewitsch; LL, lateral lemniscus; dMe, deep mesencephalic nucleus; DN, dentate nucleus; $P A G$, periaqueductal gray; DpG, deep layer of the superior colliculus; FN, fastigial nucleus; $\mathrm{Gi}$, gigantocellular reticular nucleus; Gr, gracile nucleus; IC, inferior colliculus; InC, interstitial nucleus of Cajal; InG, intermediate gray layer of the superior colliculus; InW, intermediate white layer of the superior colliculus; KF, Kölliker-fuse nucleus; LRt, lateral reticular nucleus; MdD, dorsal medullary reticular nucleus; $M d V$, ventral medullary reticular nucleus; $M G$, medial geniculate nucleus; MVe, medial vestibular nucleus; $0 \mathrm{p}$, optic nerve layer of the superior colliculus; $\mathrm{PaR}$, pararubral nucleus; $\mathrm{PB}$, parabrachial nucleus; $\mathrm{Pn}$, pontine nucleus; $\mathrm{Pn} 0$, pontine reticular nucleus, oral; $\mathrm{PO}$, periolivary nucleus; $\mathrm{Pr} 5$, principal sensory trigeminal nucleus; $\mathrm{RN}$, red nucleus; RRF, retrorubral field; SN, substantial nigra; Sol, solitary nucleus; Sp5C, spinal trigeminal nucleus, caudal; Sp5I, spinal trigeminal nucleus, interpolar; Sp50, spinal trigeminal nucleus, oral; SpVe, spinal vestibular nucleus; SuG, superficial gray layer of the superior colliculus; tth, trigeminothalamic tract; $\mathrm{Tz}$, nucleus of the trapezoid body; VC, ventral cochlear nucleus. Scale bar, $5 \mathrm{~mm}$. found in the superior and lateral vestibular nuclei bilaterally. PRV-labeled neurons became more numerous in the contralateral red nucleus and the pararubral nucleus, and a few labeled cells were seen on the ipsilateral side of these nuclei at this time (Fig. 4A). Also, PRV-labeled neurons were found in the interstitial nucleus of Cajal (Fig. 4A) and the nucleus of Darkschewitsch bilaterally, with ipsilateral predominance. Labeled neurons were also found in the oculomotor nucleus, supraoculomotor nucleus (Fig. $4 A$ ) bilaterally, and periaqueductal gray (Fig. 4B) mostly ipsilaterally. Some PRV-labeled neurons were also seen in the lateral lemniscus, mainly ipsilaterally (Fig. 4B). More importantly, the first labeled neurons in the DCN were seen at this time in the dorsolateral AIN and rostral fastigial nucleus ipsilaterally (Fig. 4C,D). It should be noted that the PRV-labeled neurons found in the AIN $4.5 \mathrm{~d}$ after PRV injection were located in a region that has been extensively implicated in eyeblink conditioning. In addition, electrical stimulation of dorsolateral AIN neurons can generate blink responses (Lavond et al., 1984; Steinmetz et al., 1992; Thompson and Steinmetz, 2009). The fastigial nucleus projects primarily to vestibular and reticular nuclei and its rostral part is involved in vestibulospinal control, including regulation of muscle tone (Gardner and Fuchs, 1975; Büttner et al., 1991; Siebold et al., 1997).

Five days after PRV injection, an increase in PRV-labeled neurons was seen throughout. In addition to previously labeled regions, labeled neurons were found in the cuneate (Fig. 6A), and gracile nucleus bilaterally. Labeled neurons were seen in the superficial gray and optic nerve layer of the contralateral superior colliculus (Fig. 6B) (McCormick et al., 1983; Halverson et al., 2009). An increase in labeling was seen in the pararubral nucleus, the deep mesencephalic nucleus, and periaqueductal gray bilaterally (Fig. 6C). A few labeled neurons were seen in the substantia nigra, mainly ipsilaterally. At this time, an increase in labeling was seen in the DCN. Labeled neurons were found in specific regions of the fastigial, interpositus, and dentate nuclei bilaterally with ipsilateral predominance.

Only two discrete regions in the ipsilateral cerebellar cortex showed PRV-labeled Purkinje cells at this time. The first region corresponds to lobule HVI in the longitudinal zone C3 (Fig. $6 D, F)$. Interestingly, HVI has been extensively implicated in delay eyeblink conditioning (Yeo et al., 1985; Schreurs et al., 1991; Gould and Steinmetz, 1996; Schreurs et al., 1997; Schreurs et al., 1998; Jirenhed et al., 2007; Kellett et al., 2010). Purkinje cells in HVI can generate a blink response and can be activated by periocular stimulation (Berthier and Moore, 1986; Hesslow, 1994). In addition, these Purkinje cells receive inputs from climbing fibers that also send collaterals to the AIN (Yeo et al., 1985; Pijpers et al., 2005; Sugihara and Shinoda, 2007).

The location of PRV-labeled Purkinje cells was determined by careful analysis of their location using three different rabbit brain atlases (McBride and Klemm, 1968; Girgis and Shih-Chang, 1981; Shek et al., 1986) and publications by Ramnani and Yeo (1996), Kellet et al. (2010), and Vogel et al. (2009). PRV-labeled 
caudal

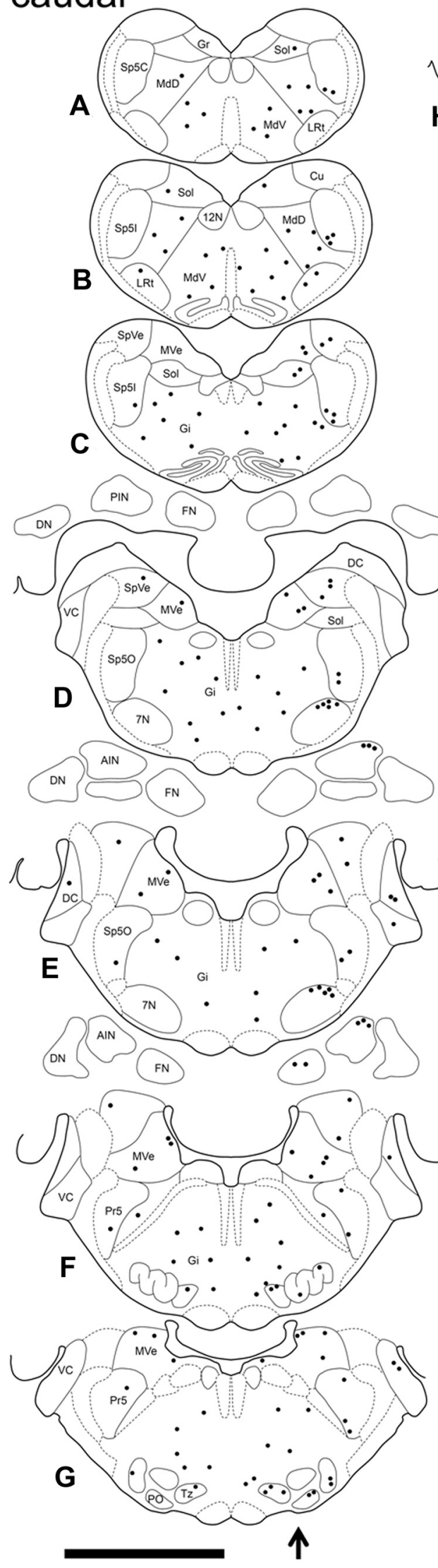

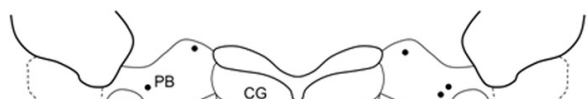

H
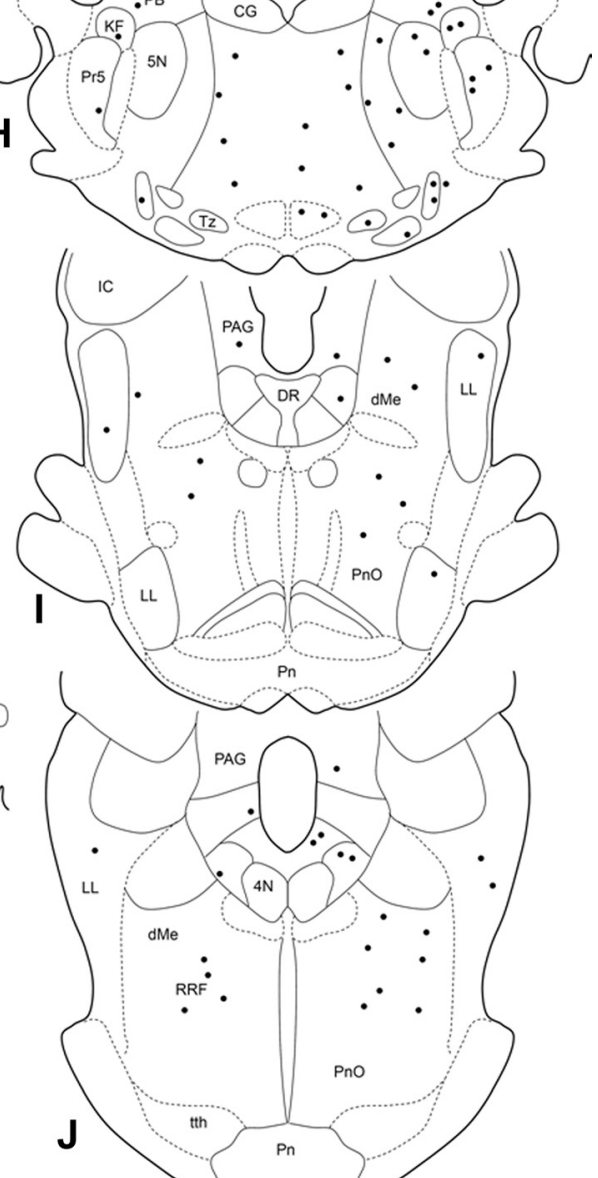

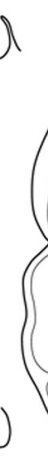

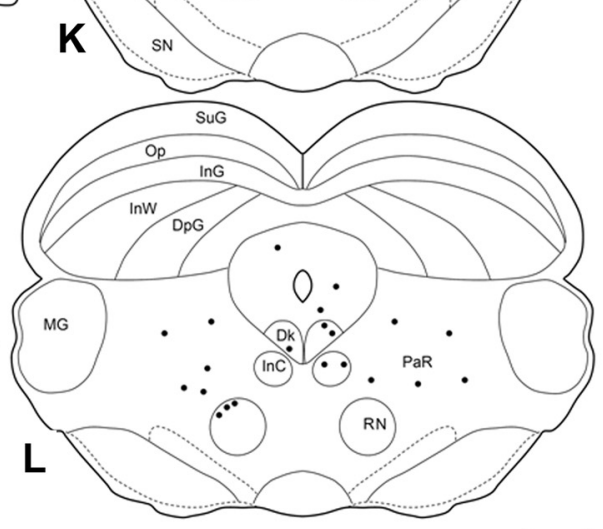

rostral

Figure 5. Distribution of PRV-labeled neurons in the brain $4.5 \mathrm{~d}$ after PRV injection in the right $00 \mathrm{M}$. A composite of the location of PRV-labeled neurons found across four animals plotted in sequential sections to best represent the pattern of PRV labeling. Sections are arranged caudorostrally $(\boldsymbol{A}-\boldsymbol{L})$. The arrow indicates the side of PRV injection. Each dot represents one PRV-labeled neuron. See Figure 3 for abbreviations. Scale bar, $5 \mathrm{~mm}$. 


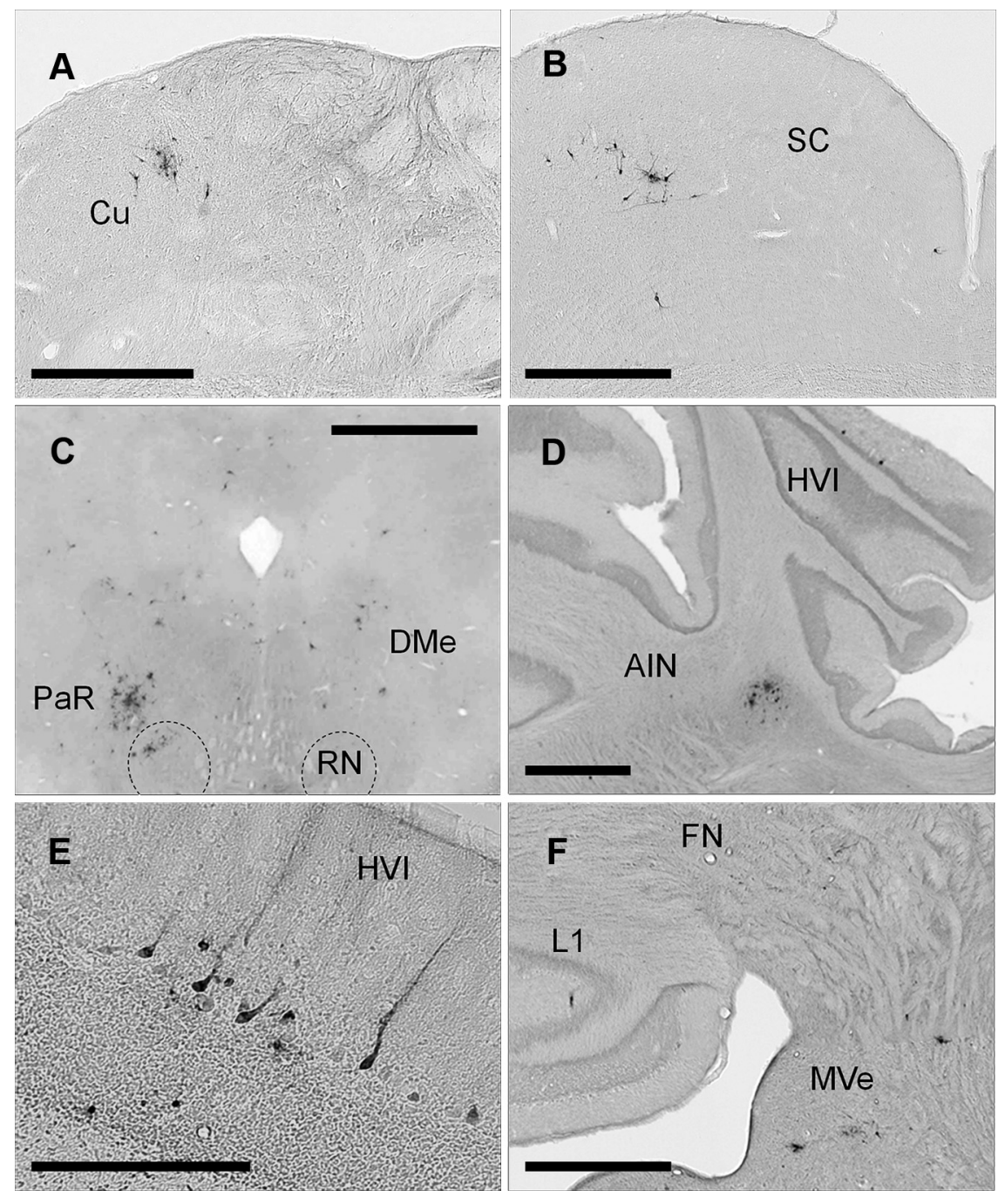

Figure 6. $\quad \boldsymbol{A}-\boldsymbol{F}$, Examples of PRV-labeled premotor neurons $5 \mathrm{~d}$ after injection. $\boldsymbol{A}$ shows PRV-labeled neurons in the $\mathrm{Cu}$ (cuneate nucleus) ipsilaterally. $\boldsymbol{B}$ shows PRV-labeled neurons in the superior colliculus (SC) contralaterally. ( shows PRV labeling in the red nucleus (RN) and pararubral nucleus (PaR) mainly contralaterally and deep mesencephalic nucleus (DMe) bilaterally. $\boldsymbol{D}$ shows PRV-labeled neurons in HVI longitudinal zone C-3 ipsilaterally; note AIN PRV-labeled neurons in the same section. $\boldsymbol{E}$ shows a group of PRV-labeled Purkinje cells in HVI zone C-3 ipsilaterally. $\boldsymbol{F}$ shows PRV-labeled cerebellar lobule I (L1) longitudinal zone A ipsilaterally, note PRV-labeling in the rostral fastigial nucleus (FN), lateral and medial vestibular nucleus (MVe) ipsilaterally. Scale bars: $\boldsymbol{A}-\boldsymbol{D}, \boldsymbol{F}, 1 \mathrm{~mm} ; \boldsymbol{E}, 200 \mu \mathrm{m}$.

Purkinje cells were located in a small region of HVI. This region corresponds to the dorsolateral posterior portion of HVI, adjacent to the ventromedial region of the paramedian lobule. Labeled Purkinje cells were found in the same coronal plane as the anterior interpositus nucleus and located -3.0 through -4.0 $\mathrm{mm}$ relative to lambda based on the coordinates used by Yeo and colleagues (Kellett et al., 2010; Ramnani and Yeo, 1996), and 0.0 $\mathrm{mm}$ through $1.0 \mathrm{~mm}$ anterior to lambda based on the coordinates used by Vogel et al. (2009). Based on their direct connection to the AIN and their topographical and anatomical location, labeled Purkinje cells were located in longitudinal zone C3. Further comparison with the Sanchez et al. (2002) study of the parasagittal compartmentalization of the rabbit cerebellar cortex revealed by the expression of zebrin II $+/-$ stripes shows that PRV-labeled Purkinje cells were located between zebrin II $+/-$ stripes p4+ and $55+$ of HVI, and most probably in $\mathrm{p} 4-$. The pattern of expression of zebrin II +/ - stripes is highly reproducible between individuals and conserved across species (Brochu et al.,
1990; Sanchez et al., 2002; Sillitoe et al., 2005). Purkinje cells located in zebrin II $+/-$ stripe $\mathrm{p} 4$ - have been shown to project to AIN in mice and rats (Sugihara and Shinoda, 2007; Sugihara and Quy, 2007; Sugihara, 2011), and in the rabbit it may correspond to $\mathrm{p} 4 \mathrm{~b}-$ (Sanchez et al., 2002). However, in the present study, the location of PRV-labeled Purkinje cells within a specific zebrin II +/- stripe can only be inferred.

The second region of Purkinje cell labeling corresponds to the rostral part of lobule I in longitudinal zone A (Fig. 6E). Purkinje cells located in lobule I longitudinal zone A have been shown to project to the fastigial nucleus (Armstrong and Schild, 1978). Labeled Purkinje cells in lobule I may be part of a cortico-nucleovestibular pathway involved in controlling the tone and position of the eyelid with respect to the eyeball and may serve as a muscle position and motion detector to modulate the coordination of different muscles during eyelid movements (Shaikh et al., 2005; Brooks and Cullen, 2009). The distribution of labeled Purkinje cells seems to delineate two distinct cerebellar OOM premotor pathways. The first involves HVI, AIN, red nucleus, and facial nucleus, whereas the second may involve lobule I, fastigial nucleus, vestibular nucleus, and facial nucleus. Together, these data show a comprehensive map of the premotor pathway of the OOM and important structures involved in the eyeblink response.

\section{PRV rate of spread}

We found that PRV consistently traced the same pathway in a time-dependent manner across all subjects. PRV axonal transport and the replication cycle seem to be dependent on viral titer, neuronal activity, strength of functional synapses, and species. Axonal transport has been estimated to occur at rates of $8-12 \mathrm{~mm} / \mathrm{h}$ in vivo (Tomishima et al., 2001) and on average, the virus's complete replication cycle in the nervous system is $\sim 6-16 \mathrm{~h}$ to the point of egress (Whealy et al., 1988; Ugolini, 2011). It has been suggested that postsynaptic neurons that innervate the soma and make numerous synapses onto an infected cell may become infected sooner than those making distal and fewer contacts (Song et al., 2005). Likewise, neuronal activity seems to influence the rate of PRV labeling and this is supported by our data. Neurons in the red nucleus that project to the facial nucleus are phasically active (Gibson et al., 1985), whereas DCN neurons are tonically active. PRV labeled the red nucleus (second-order neurons) in $24 \mathrm{~h}$ and DCN (third-order neurons) in $12 \mathrm{~h}$, even though PRV had to travel the same distance. In addition, PRV labeled fourth-order Purkinje cells (that are also tonically active) in $12 \mathrm{~h}$, suggesting that the time-dependent spread of PRV correlates with neuronal activity rather than 


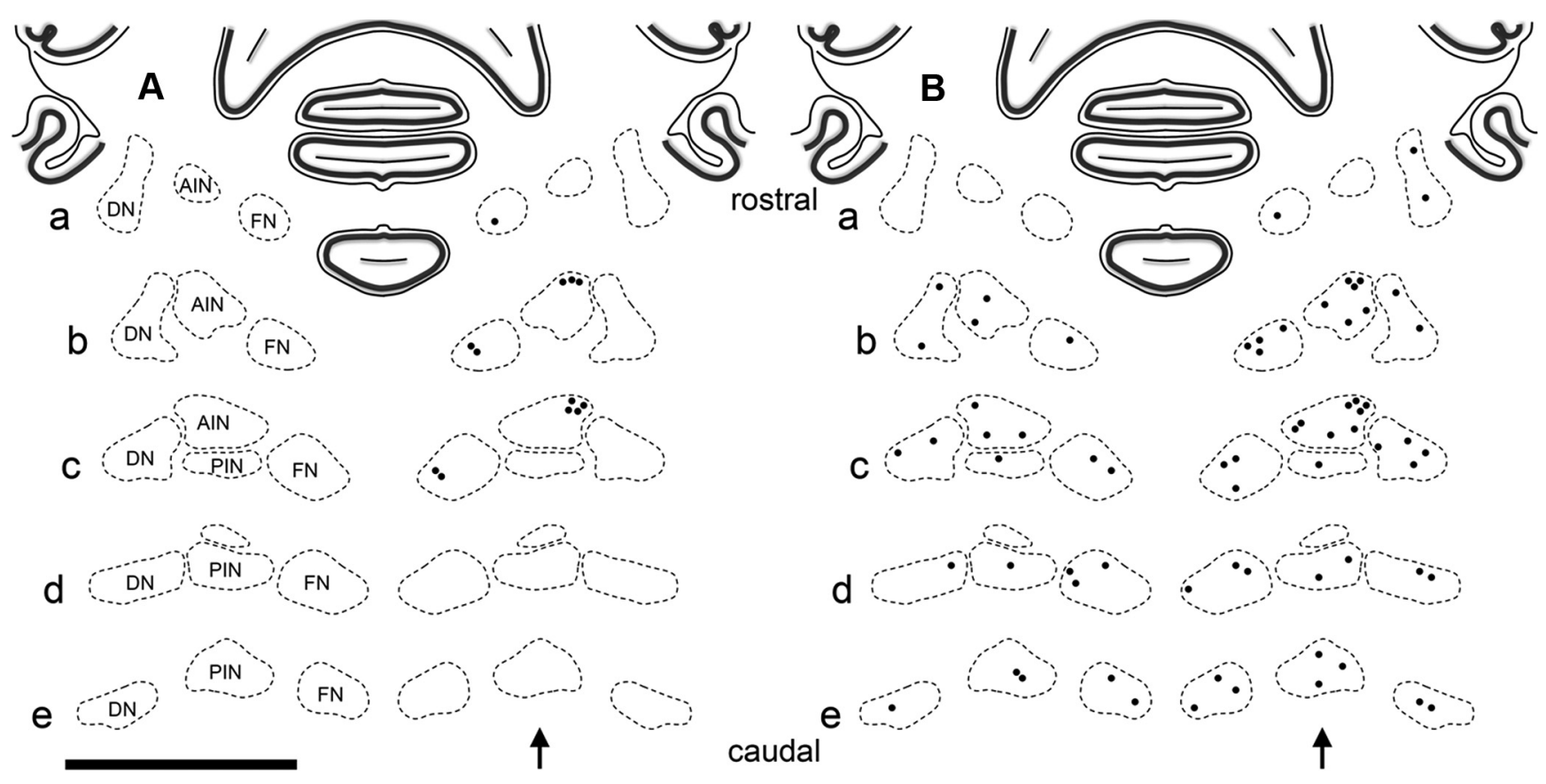

Figure 7. Distribution of PRV-labeled premotor neurons in the DCN 4.5 and $5 \mathrm{~d}$ after PRV injection. Sections are arranged rostrocaudally ( $\boldsymbol{a}-\boldsymbol{e}$ ). Note each dot represents a group of $2-5$ PRV-labeled neurons of a typical subject. $A$ shows the distribution of PRV-labeled neurons in the rostral fastigial nucleus (FN) and dorsolateral AIN that are found exclusively on the ipsilateral side 4.5 d after PRV-injection. $B$ shows the distribution of PRV-labeled neurons in the FN, AIN, posterior interpositus nucleus (PIN), and dentate nucleus (DN) that are found bilaterally with ipsilateral predominance $5 \mathrm{~d}$ after PRV injection. Scale bar, $5 \mathrm{~mm}$.

distance traveled, and it could be of particular importance for delineating functionally relevant pathways.

\section{Distribution of premotor neurons in the DCN}

To further characterize the distribution of DCN premotor neurons, the location of PRV-labeled cells 4.5 and $5 \mathrm{~d}$ after injection was plotted in a map of coronal sections. The first PRV-labeled neurons seen in the DCN at $4.5 \mathrm{~d}$ were consistent with third-order premotor neurons and were found in the dorsolateral AIN and rostral fastigial nucleus exclusively on the ipsilateral side at this time (Fig. 7A). These two distinct areas may hold particular importance in the cerebellar premotor pathway of the OOM. An increase in PRV labeling was seen bilaterally in the DCN $5 \mathrm{~d}$ after injection (Fig. $7 B$ ). At this time, groups of large and small PRV-labeled neurons were seen in all three nuclei consistent with third and fourth-order neurons. The distributions of these neurons could be of importance in elucidating the somatotopic organization of the OOM in all three nuclei.

\section{Neurotransmitter immunoreactivity in} the AIN

The large and small PRV-labeled neurons seen in the ipsilateral AIN $5 \mathrm{~d}$ after injection (Fig. $7 B$ ) were presumably thirdorder glutamatergic projection neurons and fourth-order interneurons. To fur-

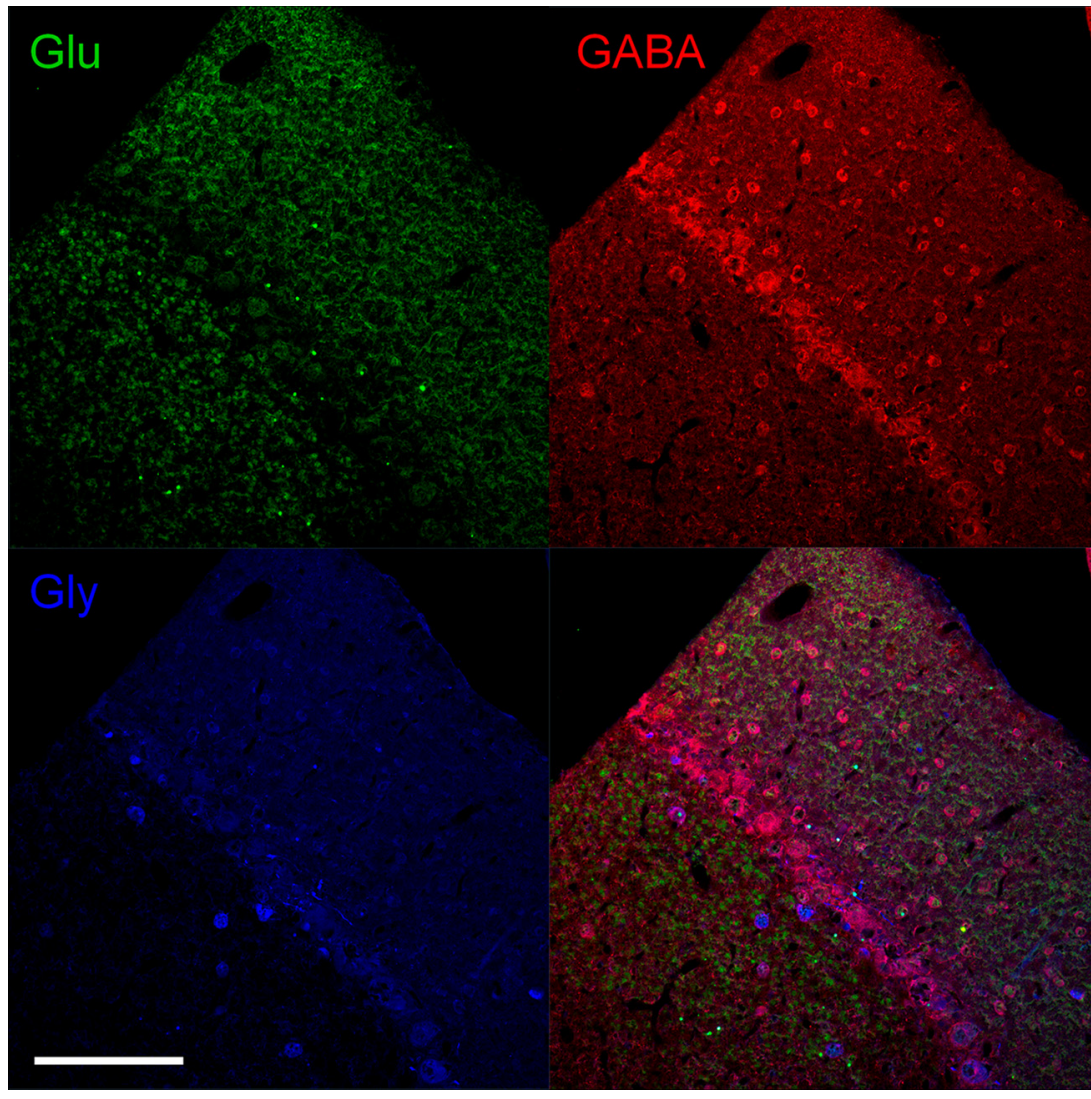

Figure 8. Glutamate, GABA, and glycine immunoreactivity in the cerebellar cortex. Glutamate-immunoreactive granule cells and their numerous axon terminals extending through the molecular layer are seen in the top left panel. GABA-immunoreactive neurons including Purkinje cells, basket, and stellate cells in the molecular layer, and Golgi cells in the granule cell layer are shown in the top right panel. Glycine-immunoreactive neurons in the cerebellar cortex including Lugaro cells in the Purkinje cell layer, and Golgi cells in the granule cell layer are shown in the bottom left panel. A merged image of glutamate-, GABA-, and glycine-immunoreactive neurons is shown in the bottom right panel. Colocalization of GABA and glycine-immunoreactive neurons can be seen in some Golgi and Lugaro cells. Glu, Glutamate; Gly, glycine. Scale bar, $200 \mu \mathrm{m}$. 


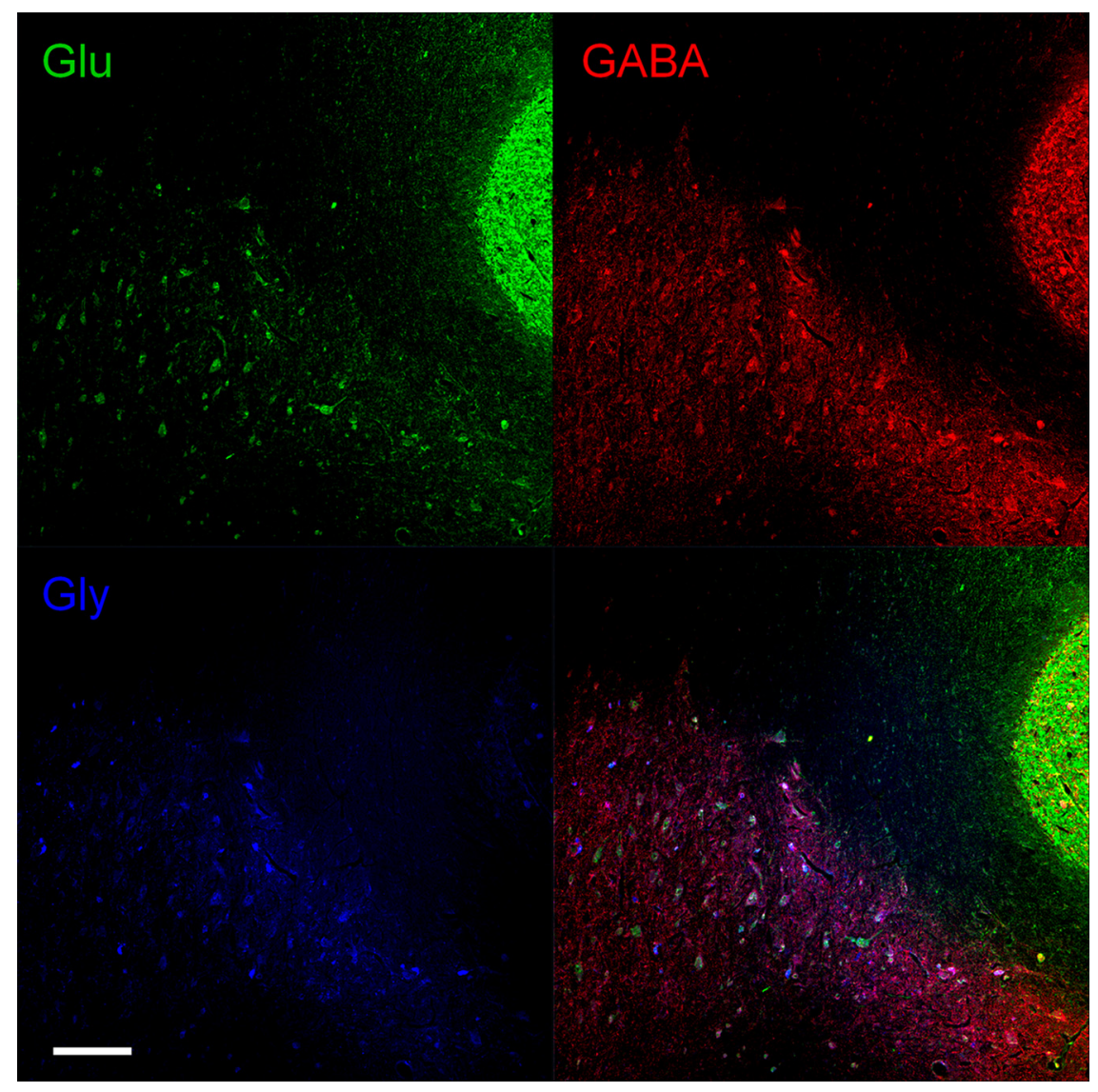

Figure 9. Glutamate, GABA, and glycine immunoreactivity in the DCN and cerebellar cortex. A section that contains the dorsolateral AIN, dorsal dentate nucleus (DN), and the granule cell layer of the cerebellar cortex is shown. Glutamate-immunoreactive neurons are shown in the top left panel. Note large glutamate-immunoreactive neurons in the DCN and numerous granule cells in the cerebellar cortex. GABA-immunoreactive neurons are shown in the top right panel. Note smaller GABA-immunoreactive neurons and numerous terminals in the DCN and several Golgi cells in the granule cell layer. Glycine-immunoreactive neurons are shown in the bottom left panel. Note small distinctive glycine-immunoreactive neurons evenly distributed in the DCN. A merged image of glutamate, GABA, and glycine-immunoreactive neurons is shown in the bottom right panel. Glu, Glutamate; Gly, glycine. Scale bar, $400 \mu \mathrm{m}$.

ther investigate this local network, we used glutamate, GABA, and glycine immunoreactivity to label these neurons. All sections containing the ipsilateral DCN were immunolabeled, and as a control, the cerebellar cortex was examined in each section to confirm the specificity of neurotransmitter immunoreactivity. Figure 8 shows glutamate-, GABA-, and glycine-immunoreactive neurons in the cerebellar cortex. Granule cells and their numerous axon terminals extending through the molecular layer were immunoreactive for glutamate. Purkinje cells, small basket and stellate cells in the molecular layer, and Golgi cells in the granule cell layer were immunoreactive for GABA. Neurons immunoreactive for glycine include Lugaro cells in the Purkinje cell layer and Golgi cells in the granule cell layer. Colocalization of GABA and glycine immunoreactivity can be seen in some Golgi and Lugaro cells in the granule cell layer, known to be GABA/glycinergic neurons (Crook et al., 2006; Simat et al., 2007).

Glutamate-, GABA-, and glycine-immunoreactive neurons in the DCN including the AIN, dentate nucleus, and granule cell layer of the cerebellar cortex are shown in Figure 9. Large neurons in the DCN and small granule cells in the cerebellar cortex are glutamate immunoreactive. Small neurons and numerous terminals in the DCN are GABA immunoreactive. In addition, several Golgi cells in the granule cell layer in the same section are also GABA immunoreactive. Glycineimmunoreactive neurons are small and evenly distributed in the DCN. In addition, glutamate was found to colocalize with most GABA-immunoreactive neurons to various degrees. Because glutamate is a precursor of GABA, it is present in GABAergic cells as a function of their metabolic state (Ottersen and StormMathisen, 1984; Sultan et al., 2002). Also, glutamate labeling was never found in purely glycine-immunoreactive neurons. However, GABA/glycine-immunoreactive neurons showed glutamate labeling to various degrees. Consequently, glutamateimmunoreactive neurons were classified as glutamatergic only when they did not colocalize with other neurotransmitters. An example of a $4.5 \mathrm{~d}$ PRV-labeled neuron immunoreactive for glutamate is shown in Figure 10. PRV-labeled neurons immunoreactive for glutamate were large $(29 \mu \mathrm{m}$; range $21-27 \mu \mathrm{m}$ ), and an average of 20 neurons (range 13-27) were found in the AIN 4.5 dafter injection.

Next, characterization of PRV-labeled neurons $5 \mathrm{~d}$ after injection revealed an average of 34 (range 25-43) glutamateimmunoreactive neurons and an average of 66 (range 54-78) interneurons immunoreactive for GABA and/or glycine. The interneurons were immunoreactive for GABA (30\%), glycine (18\%), or for both GABA and glycine (52\%). The average soma diameter for PRV-labeled interneurons immunoreactive for GABA was 16 $\mu \mathrm{m}$ (range 12-20 $\mu \mathrm{m}$ ), for glycine $15 \mu \mathrm{m}$ (range 11-19 $\mu \mathrm{m}$ ), and for GABA/glycine $17 \mu \mathrm{m}$ (range $12-22 \mu \mathrm{m}$ ). An example of a PRV-labeled interneuron $5 \mathrm{~d}$ after injection is shown in Figure 11. In this case, a PRV-labeled interneuron is immunoreactive for both GABA and glycine. We were able to follow the PRV-labeled axon of this neuron and found its terminal apposed to an adjacent interneuron that was also GABA/glycine-immunoreactive. Interestingly, the terminal of the PRV-labeled interneuron was glycine immunoreactive only, suggesting that mixed GABA/glycinergic interneurons in the DCN can selectively release either neurotransmitter from their terminals. Differential neurotransmitter release from mix GABA/glycinergic neurons has been previously hypothesized (Dumoulin et al., 2001; Dugué et al., 2005; Dufour et al., 2010; Benarroch, 2011)

\section{Discussion}

The present study shows the premotor pathway of the rabbit OOM using PRV as a retrograde transneuronal tracer. Relevant structures involved in the generation or modulation of the rabbit eyeblink response were identified and provide anatomical validation of a direct premotor network that involves the dorsolateral AIN of the DCN and HVI of the cerebellar cortex, which have been implicated in eyeblink conditioning. Of particular importance, classification of fourth-order premotor interneurons based on their neurotransmitter immunoreactivity revealed three 


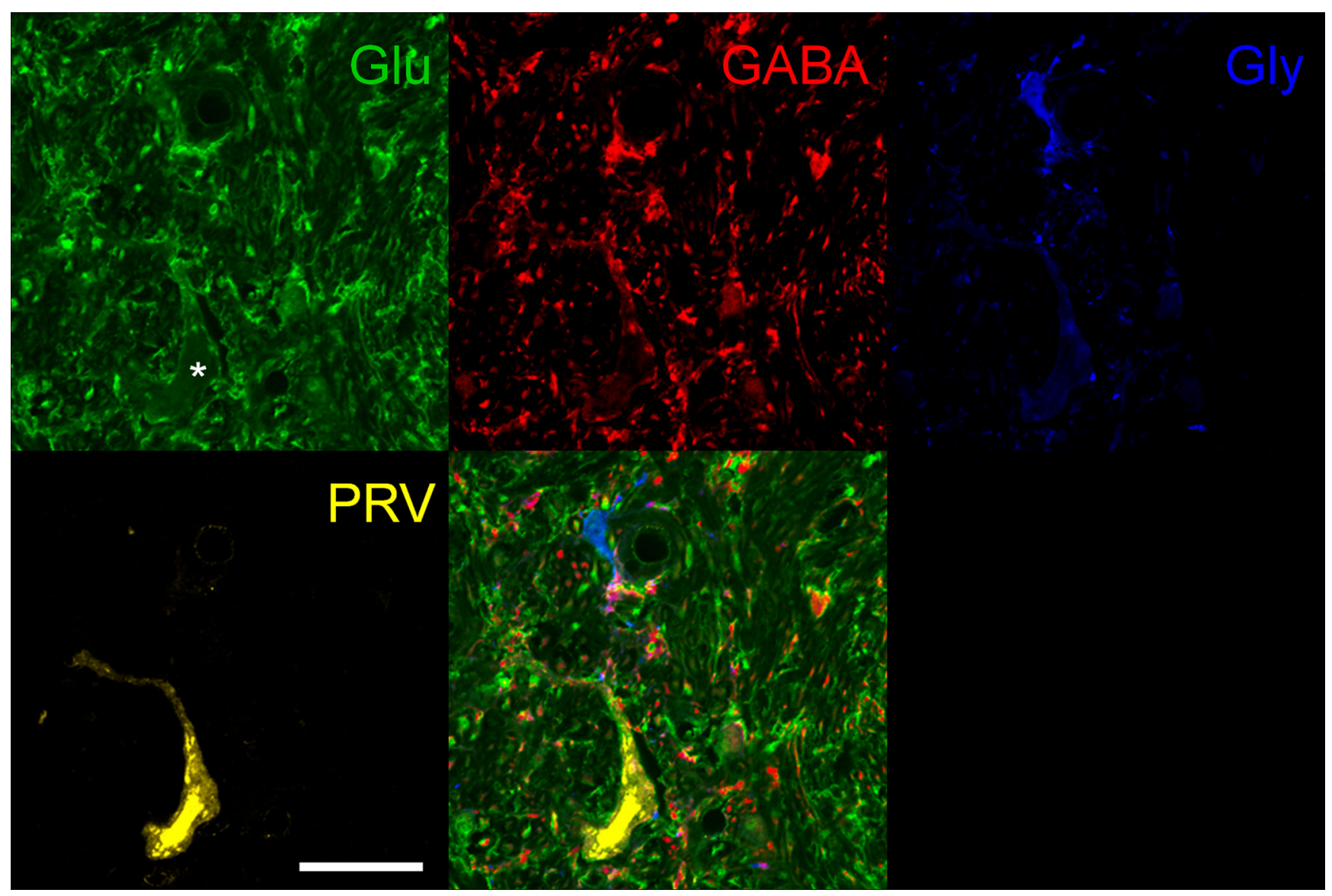

Figure 10. Glutamate immunoreactive PRV-labeled neuron in the AIN $4.5 \mathrm{~d}$ after injection into the 00M. Glutamate immunoreactivity is shown in the top left panel. Note a large glutamateimmunoreactive neuron at the bottom of the panel indicated by the asterisk. GABA-immunoreactivity is shown in the top middle panel. Four GABA-immunoreactive interneurons are visible and note the presence of glutamate immunoreactivity in their cell bodies. Numerous GABA-immunoreactive terminals are evident apposed to different neuronal processes and glutamate-immunoreactive somas. Glycine-immunoreactivity is shown in the top right panel. Note a small interneuron that is exclusively glycine-immunoreactive. A few glycine-immunoreactive terminals apposing dendrites and somas of glutamate-immunoreactive and GABA-immunoreactive neurons are shown. A PRV-labeled neuron is shown in the bottom left panel. A merged image of glutamate-, GABA-, and glycine immunoreactivity and PRV is shown in the bottom right panel. Note that the PRV-labeled neuron colocalizes with a large glutamate-immunoreactive neuron. A small interneuron immunoreactive for both GABA and glycine is also shown. Glu, Glutamate; Gly, glycine. Scale bar, $40 \mu \mathrm{m}$.

different types of inhibitory interneurons that are part of the OOM premotor pathway and form a functional network within the AIN for the modulation of motor commands.

\section{Premotor pathway of the rabbit OOM}

At $3 \mathrm{~d}$ after PRV injection, first-order motor neurons were found ipsilaterally in the dorsolateral facial nucleus. At $4 \mathrm{~d}$, the dorsolateral magnocellular red nucleus was labeled contralaterally. At $4.5 \mathrm{~d}$, third-order premotor neurons were found in dorsolateral AIN and the rostral fastigial nucleus ipsilaterally. At $5 \mathrm{~d}$, the fastigial, interpositus, and dentate nucleus were labeled bilaterally with ipsilateral predominance. A number of fourth-order Purkinje cells were found in two cerebellar cortex locations, HVI zone C3 and lobule I zone A, and two distinct pathways were discerned. The first involves HVI, AIN, red nucleus, and facial nucleus, and the second may involve lobule I, fastigial nucleus, vestibular nucleus, and facial nucleus. In addition, second- and third-order premotor neurons were found in reticular nuclei and sensory trigeminal, auditory, vestibular, and motor structures. These may constitute secondary pathways and are no doubt involved in the modulation of eyelid movements by other response systems (e.g., startle, orientation, attention). These higher-order pathways have been reviewed extensively by Morcuende et al. (2002).

\section{Cerebellar cortex}

There is an ongoing controversy about which lobules in cerebellar cortex control conditioned eyeblinks. Rabbit lesion, infusion, and recording studies have implicated HVI in eyeblink conditioning (Berthier and Moore, 1986; Gould and Steinmetz, 1996; Attwell et al., 2001). More recent studies suggest anterior lobules HIV and HV are also involved in conditioning (Garcia et al., 1999; Green and Steinmetz, 2005; Kalmbach et al., 2010). However, the functional organization of cerebellar cortex is consistent with longitudinal zones that span multiple lobules, and regions controlling the rabbit eyelid may not be confined to a single lobule. In fact, there are multiple eyelid microzones in cerebellar cortex that receive climbing fiber inputs during periocular stimulation, exhibit eyeblink-related activity patterns, and project to the AIN. An additional rabbit eyelid microzone has been identified in the ventral portion of HVI (Mostofi et al., 2010). It is conceivable that different eyeblink microzones encode different types of information including time, position, intensity, and duration, and that together these microzones convey information to their target nuclear cells that then elicit a motor command.

To date, it is not clear how Purkinje cell activity controls eyelid movement. On the one hand, a pause in inhibitory, tonically active Purkinje cells allows target nuclear cells to produce the necessary activation required to generate a motor command. On 


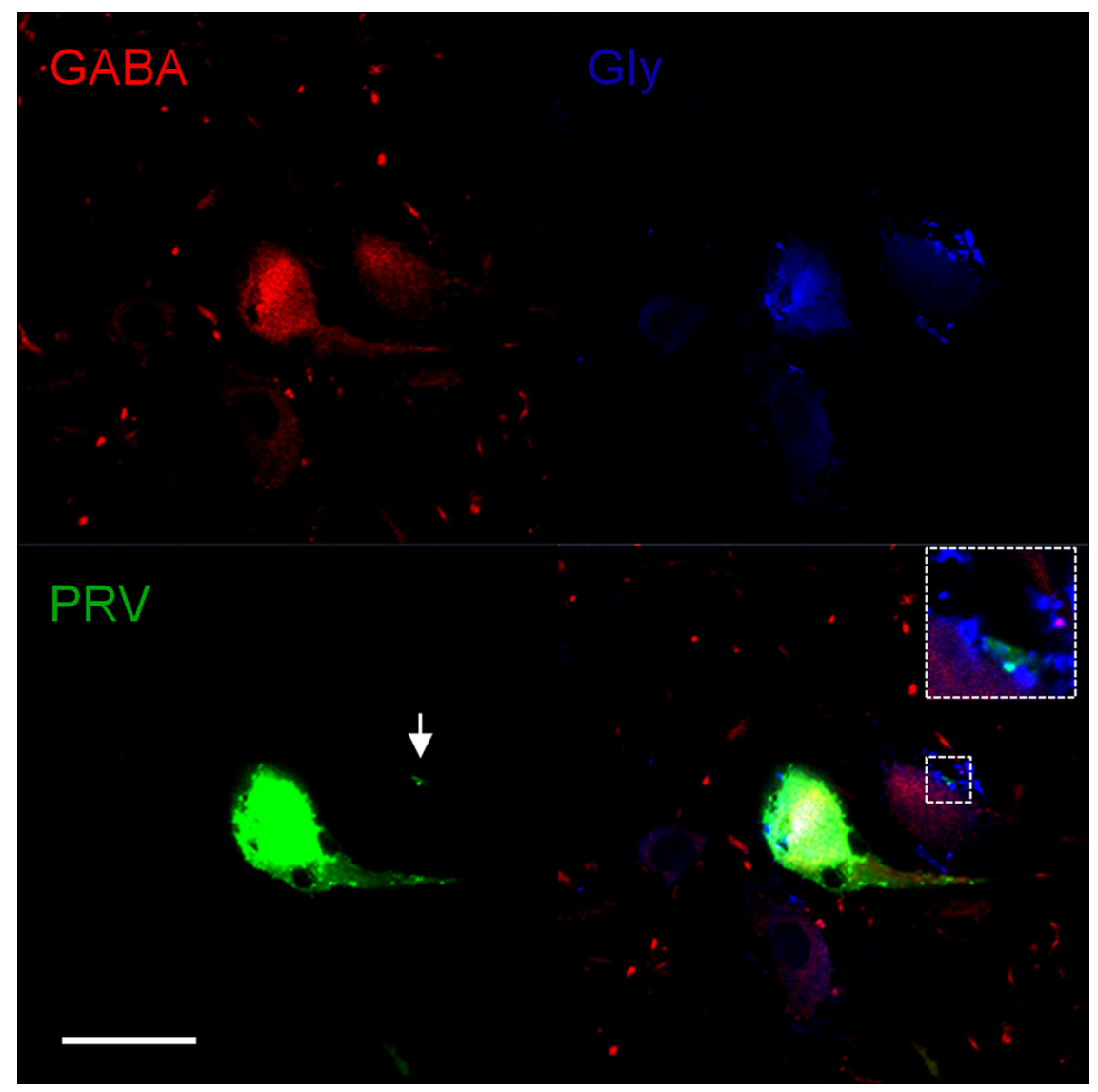

Figure 11. GABA and glycine immunoreactive interneuron labeled with PRV. GABA immunoreactivity is shown in the top left panel. Note two GABA-immunoreactive interneurons and numerous GABA-immunoreactive terminals. Glycine immunoreactivity is shown in the top right panel. Note two Glycine-immunoreactive interneurons and a few and densely packed Glycineimmunoreactive terminals. PRV-labeled fourth-order interneuron and its PRV-labeled terminal are shown in the bottom left panel. A merged image of GABA immunoreactivity, glycine immunoreactivity, and PRV is shown in the bottom right panel. Note that the PRV-labeled interneuron is immunoreactive for both GABA and glycine and its PRV-labeled terminal is immunoreactive solely for glycine. Glu, Glutamate; Gly, glycine. Scale bar $20 \mu \mathrm{m}$.

the other hand, a burst of Purkinje cell activity may produce inhibition of target nuclear cells that is followed by rebound depolarization that results in a motor command (Pugh and Raman, 2006; Alviña et al., 2008; Molineux et al., 2008). Recordings from eyeblink microzones show that some Purkinje cells increase their firing rate while others decrease their firing during performance of a conditioned eyeblink response.

\section{The microcircuit of the AIN}

Information processed in the cerebellum is integrated in the DCN where motor commands are generated and executed. Despite their importance, little is known about the components that constitute this local network and their interconnections. Potential interactions among interneurons in the DCN and their role in learning are largely unknown. The AIN has been implicated in eyeblink conditioning, and synaptic changes responsible for a conditioned response are hypothesized to occur in this nucleus. Lesion and inactivation studies show that the AIN is critical for conditioned responses (Lavond et al., 1984; Steinmetz et al., 1992; Krupa and Thompson, 1997). Single unit recordings in AIN show some neurons increase their firing rate during conditioned responses in a pattern that precedes and predicts the response (McCormick and Thompson, 1984). In vitro studies in the interpositus show large neurons can undergo different types of synaptic plasticity, including LTP and LTD (Pugh and Raman, 2006). Recently, the electrophysiological properties of DCN interneurons have been studied in transgenic mice expressing GAD-eGFP or GlyT2-eGFP (Uusisaari and Knöpfel, 2011). However, little is known about the synaptic connections and interactions among the different neuronal types.

Our results show three types of interneurons that are directly connected to large glutamatergic projection neurons and possibly involved in modulating their output. The DCN is a complex structure and different components and interactions contribute to the integration of a final cerebellar output. Here, we show a local network within AIN consisting of a glutamatergic projection neuron and three types of inhibitory interneurons that are part of the OOM premotor pathway. PRV-labeled fourth-order interneurons were immunoreactive for GABA, glycine, or both GABA and glycine. Interconnectivity was found in a PRV-labeled mixed GABA/glycinergic interneuron in which we were able to follow the axon. The terminal of this interneuron was labeled with PRV and apposed the soma of another GABA/glycinergic-immunoreactive interneuron that was not labeled with PRV, suggesting these two interneurons contact different glutamatergic neurons. GABA and glycine are frequently coexpressed in the same cell and coreleased from the same terminals (Ottersen et al., 1988; Dumoulin et al., 2001; Dugué et al., 2005). Mixed GABA/glycinergic neurons are thought to modulate the ratio of neurotransmitter release as these neurotransmitters have different effects on their postsynaptic targets (Benarroch, 2011). Interestingly, the synaptic terminal of the PRV-labeled mixed GABA/ glycinergic interneuron was immunoreactive solely for glycine, suggesting differential neurotransmitter release. Glycine has been implicated in different types of synaptic plasticity, including LTP (Martina et al., 2004), and is required for the activation of NMDA receptors (Johnson and Ascher, 1987), suggesting another possible mechanism of plasticity in AIN.

Based on the observed interconnectivity of interneurons described above and current knowledge of AIN organization, a schematic diagram of possible interactions is depicted in Figure 12. The figure shows Purkinje cell inhibitory inputs as well as excitatory mossy fiber and climbing fiber collateral inputs arriving at large glutamatergic projection neurons. Also depicted are Purkinje cell inhibitory inputs and presumed mossy fiber and climbing fiber collateral projections to interneurons that provide their only excitatory input. Finally, the figure proposes inhibitory connections between interneurons. These connections allow one to speculate about the consequences of interactions among and between interneurons and projection neurons. For example, although mossy fiber and climbing fiber collaterals activate a PRVpositive glutamatergic projection neuron, they also activate inhibitory interneurons that, in turn, inhibit adjacent PRV- 
negative projection neurons creating an inhibitory surround. In addition, the inhibitory interneuron contacted by these mossy fiber and climbing fiber collaterals also synapses onto a second interneuron, which, in turn, disinhibits the PRVpositive projection neuron. As a result of releasing inhibition, sensory inputs could increase excitation of the PRV-positive projection neuron while indirectly inhibiting adjacent PRV-negative projection neurons. These interactions are modulated by Purkinje cell inhibition. One consequence of this combination of excitation and inhibition of projection neurons could be coordination of the OOM and levator palpebrae, allowing closure of the eyelids (Sánchez-Campusano et al., 2012). In the case of eyeblink conditioning, increased Purkinje cells inhibition of the inhibitory interneurons apposing a projection neuron would increase the likelihood of that cell firing and producing a conditioned response.

\section{Comparison with other transsynaptic studies of the OOM}

A study in mouse using PRV (Sun, 2012) and another in rat using rabies virus (Morcuende et al., 2002) also delineated the eyeblink premotor pathway. Despite some similarities, there are significant differences between our results and those of Sun (2012). Although motor neurons were found in ipsilateral facial nucleus after PRV injection, labeling was also found in ventral and dorsal red nucleus bilaterally, rather than our contralateral labeling in dorsolateral red nucleus that agrees with previous research (Takada et al., 1984; Holstege and Tan, 1988). This suggests Sun (2012) may have identified pathways not directly connected to the facial nucleus because averaging across different time points combined different synaptic steps. This is true for the cerebellum as well because of extensive bilateral labeling of all three deep nuclei as well as bilateral labeling throughout the cerebellar cortex. Thus, a direct premotor pathway from cerebellum to the facial nucleus may have been present in PRV-injected mice, but it was obscured by more indirect pathways.

An earlier study of the rat OOM premotor pathway was performed using rabies (Morcuende et al., 2002) and corresponds well with the rabbit OOM premotor pathway identified using PRV, at least to the level of third-order premotor neurons. Morcuende et al. (2002) found rabies-labeled neurons in caudolateral AIN and dorsolateral hump of DCN, whereas in the rabbit, third-order neurons were located in dorsolateral AIN and the rostral fastigial nucleus. In addition, they found fourth-order labeled Purkinje cells in the vermis and paravermis zones $\mathrm{C} 1-\mathrm{C} 3$, whereas in the rabbit, fourthorder Purkinje cells were found exclusively in HVI zone C3 and Lobule I zone A. These differences may reflect anatomical or functional differences between species or variations in viral kinetics.

\section{References}

Alviña K, Walter JT, Kohn A, Ellis-Davies G, Khodakhah K (2008) Questioning the role of rebound firing in the cerebellum. Nat Neurosci 11:1256-1258.

Armstrong DM, Schild RF (1978) An investigation of the cerebellar corticonuclear projections in the rat using an autoradiographic tracing method. I. Projections from the vermis. Brain Res 141:1-19.

Aston-Jones G, Card JP (2000) Use of pseudorabies virus to delineate multisynaptic circuits in brain: opportunities and limitations. J Neurosci Methods 103:51-61.

Aston-Jones G, Zhu Y, Card JP (2004) Numerous GABAergic afferents to locus ceruleus in the pericerulear dendritic zone: possible interneuronal pool. J Neurosci 24:2313-2321.

Attwell PJ, Rahman S, Yeo CH (2001) Acquisition of eyeblink conditioning is critically dependent on normal function in cerebellar cortical lobule HVI. J Neurosci 21:5715-5722.

Avendaño C, Machín R, Bermejo PE, Lagares A (2005) Neuron numbers in the sensory trigeminal nuclei of the rat: A. J Comp Neurol 493:538-553.

Bagnall MW, Zingg B, Sakatos A, Moghadam SH, Zeilhofer HU, du Lac S (2009) Glycinergic projection neurons of the cerebellum. J Neurosci 29:10104-10110.

Bartha A (1961) Experimental reduction of virulence of Aujesky's disease. Magy Allatorv 16:42-45.

Batini C, Compoint C, Buisseret-Delmas C, Daniel H, Guegan M (1992) 
Cerebellar nuclei and the nucleocortical projections in the rat: retrograde tracing coupled to GABA and glutamate immunohistochemistry. J Comp Neurol 315:74-84.

Benarroch EE (2011) Glycine and its synaptic interactions: functional and clinical implications. Neurology 77:677-683.

Berthier NE, Moore JW (1986) Cerebellar Purkinje cell activity related to the classically conditioned nictitating membrane response. Exp Brain Res 63:341-350.

Billig I, Foris JM, Enquist LW, Card JP, Yates BJ (2000) Definition of neuronal circuitry controlling the activity of phrenic and abdominal motoneurons in the ferret using recombinant strains of pseudorabies virus. J Neurosci 20:7446-7454.

Bonis JM, Neumueller SE, Krause KL, Kiner T, Smith A, Marshall BD, Qian B, Pan LG, Forster HV (2010) The pontine respiratory group, particularly the Kolliker-Fuse nucleus, mediates phases of the hypoxic ventilatory response in unanesthetized goats. J Appl Physiol 108:1321-1335.

Brochu G, Maler L, Hawkes R (1990) Zebrin II: a polypeptide antigen expressed selectively by Purkinje cells reveals compartments in rat and fish cerebellum. J Comp Neurol 291:538-552.

Brooks JX, Cullen KE (2009) Multimodal integration in rostral fastigial nucleus provides an estimate of body movement. J Neurosci 29:10499-10511.

Büttner U, Fuchs AF, Markert-Schwab G, Buckmaster P (1991) Fastigial nucleus activity in the alert monkey during slow eye and head movements. J Neurophysiol 65:1360-1371.

Chagnaud JL, Campistron G, Geffard M (1989) Monoclonal antibody directed against glutaraldehyde conjugated glutamate and immunocytochemical applications in the rat brain. Brain Res 481:175-180.

Chalazonitis A, Pham TD, Li Z, Roman D, Guha U, Gomes W, Kan L, Kessler JA, Gershon MD (2008) Bone morphogenetic protein regulation of enteric neuronal phenotypic diversity: relationship to timing of cell cycle exit. J Comp Neurol 509:474-492.

Chamberlin NL, Saper CB (1994) Topographic organization of respiratory responses to glutamate microstimulation of the parabrachial nucleus in the rat. J Neurosci 14:6500-6510.

Chapman PF, Steinmetz JE, Thompson RF (1988) Classical conditioning does not occur when direct stimulation of the red nucleus or cerebellar nuclei is the unconditioned stimulus. Brain Res 442:97-104.

Chen S, Yang M, Miselis RR, Aston-Jones G (1999) Characterization of transsynaptic tracing with central application of pseudorabies virus. Brain Res 838:171-183.

Crook J, Hendrickson A, Robinson FR (2006) Co-localization of glycine and gaba immunoreactivity in interneurons in Macaca monkey cerebellar cortex. Neuroscience 141:1951-1959.

Curanovic D, Enquist L (2009) Directional transneuronal spread of alphaherpesvirus infection. Future Virol 4:591.

Curanović D, Lyman MG, Bou-Abboud C, Card JP, Enquist LW (2009) Repair of the UL21 locus in pseudorabies virus Bartha enhances the kinetics of retrograde, transneuronal infection in vitro and in vivo. J Virol 83:1173-1183.

Daniel H, Billard JM, Angaut P, Batini C (1987) The interpositorubrospinal system. Anatomical tracing of a motor control pathway in the rat. Neurosci Res 5:87-112.

Daniels D, Miselis RR, Flanagan-Cato LM (1999) Central neuronal circuit innervating the lordosis-producing muscles defined by transneuronal transport of pseudorabies virus. J Neurosci 19:2823-2833.

de Zeeuw CI, Holstege JC, Ruigrok TJ, Voogd J (1989) Ultrastructural study of the GABAergic, cerebellar, and mesodiencephalic innervation of the cat medial accessory olive: anterograde tracing combined with immunocytochemistry. J Comp Neurol 284:12-35.

Dmitrieva NA, Lindstrom JM, Keyser KT (2001) The relationship between GABA-containing cells and the cholinergic circuitry in the rabbit retina. Vis Neurosci 18:93-100.

Downie LE, Hatzopoulos KM, Pianta MJ, Vingrys AJ, Wilkinson-Berka JL, Kalloniatis M, Fletcher EL (2010) Angiotensin type-1 receptor inhibition is neuroprotective to amacrine cells in a rat model of retinopathy of prematurity. J Comp Neurol 518:41-63.

Dufour A, Tell F, Kessler JP, Baude A (2010) Mixed GABA-glycine synapses delineate a specific topography in the nucleus tractus solitarii of adult rat. J Physiol 588:1097-1115.

Dugué GP, Dumoulin A, Triller A, Dieudonné S (2005) Target-dependent use of co-released inhibitory transmitters at central synapses. J Neurosci 25:6490-6498.

Dumoulin A, Triller A, Dieudonné S (2001) IPSC kinetics at identified GABAergic and mixed GABAergic and glycinergic synapses onto cerebellar Golgi cells. J Neurosci 21:6045-6057.

Fredrich M, Reisch A, Illing RB (2009) Neuronal subtype identity in the rat auditory brainstem as defined by molecular profile and axonal projection. Exp Brain Res 195:241-260.

Freeman JH, Steinmetz AB (2011) Neural circuitry and plasticity mechanisms underlying delay eyeblink conditioning. Learn Mem 18:666-677.

Garcia KS, Steele PM, Mauk MD (1999) Cerebellar cortex lesions prevent acquisition of conditioned eyelid responses. J Neurosci 19:10940-10947.

Gardner EP, Fuchs AF (1975) Single-unit responses to natural vestibular stimuli and eye movements in deep cerebellar nuclei of the alert rhesus monkey. J Neurophysiol 38:627-649.

Gibson AR, Houk JC, Kohlerman NJ (1985) Magnocellular red nucleus activity during different types of limb movement in the macaque monkey. J Physiol 358:527-549.

Girgis M, Shih-Chang W (1981) Stereotaxic atlas of the rabbit brain. St Louis, MO: Green.

Gould TJ, Steinmetz JE (1996) Changes in rabbit cerebellar cortical and interpositus nucleus activity during acquisition, extinction, and backward classical eyelid conditioning. Neurobiol Learn Mem 65:17-34.

Green JT, Steinmetz JE (2005) Purkinje cell activity in the cerebellar anterior lobe after rabbit eyeblink conditioning. Learn Mem 12:260-269.

Halverson HE, Hubbard EM, Freeman JH (2009) Stimulation of the lateral geniculate, superior colliculus, or visual cortex is sufficient for eyeblink conditioning in rats. Learn Mem 16:300-307.

Henriquez VM, Evinger C (2007) The three-neuron corneal reflex circuit and modulation of second-order corneal responsive neurons. Exp Brain Res 179:691-702.

Hesslow G (1994) Correspondence between climbing fibre input and motor output in eyeblink-related areas in cat cerebellar cortex. J Physiol 476:229-244.

Hinrichsen CF, Watson CD (1983) Brain stem projections to the facial nucleus of the rat. Brain Behav Evol 22:153-163.

Holstege G, Tan J (1988) Projections from the red nucleus and surrounding areas to the brainstem and spinal cord in the cat. An HRP and autoradiographical tracing study. Behav Brain Res 28:33-57.

Horta-Júnior JA, Tamega OJ, Cruz-Rizzolo RJ (2004) Cytoarchitecture and musculotopic organization of the facial motor nucleus in Cebus apella monkey. J Anat 204:175-190.

James P, Rivier C, Lee S (2008) Presence of corticotrophin-releasing factor and/or tyrosine hydroxylase in cells of a neural brain-testicular pathway that are labelled by a transganglionic tracer. J Neuroendocrinol 20:173-181.

Jirenhed DA, Bengtsson F, Hesslow G (2007) Acquisition, extinction, and reacquisition of a cerebellar cortical memory trace. J Neurosci 27:2493-2502.

Johnson JW, Ascher P (1987) Glycine potentiates the NMDA response in cultured mouse brain neurons. Nature 325:529-531.

Kalmbach BE, Davis T, Ohyama T, Riusech F, Nores WL, Mauk MD (2010) Cerebellar cortex contributions to the expression and timing of conditioned eyelid responses. J Neurophysiol 103:2039-2049.

Kellett DO, Fukunaga I, Chen-Kubota E, Dean P, Yeo CH (2010) Memory consolidation in the cerebellar cortex. PLoS One 5:e11737.

Kerman IA, Akil H, Watson SJ (2006) Rostral elements of sympatho-motor circuitry: a virally mediated transsynaptic tracing study. J Neurosci 26:3423-3433.

Klein BG, Rhoades RW, Jacquin MF (1990) Topography of the facial musculature within the facial (VII) motor nucleus of the neonatal rat. Exp Brain Res 81:649-653.

Komiyama M, Shibata H, Suzuki T (1984) Somatotopic representation of facial muscles within the facial nucleus of the mouse. A study using the retrograde horseradish peroxidase and cell degeneration techniques. Brain Behav Evol 24:144-151.

Krupa DJ, Thompson RF (1997) Reversible inactivation of the cerebellar interpositus nucleus completely prevents acquisition of the classically conditioned eye-blink response. Learn Mem 3:545-556.

Kuo SP, Bradley LA, Trussell LO (2009) Heterogeneous kinetics and pharmacology of synaptic inhibition in the chick auditory brainstem. J Neurosci 29:9625-9634. 
Lavond DG, Lincoln JS, McCormick DA, Thompson RF (1984) Effect of bilateral lesions of the dentate and interpositus cerebellar nuclei on conditioning of heart-rate and nictitating membrane/eyelid responses in the rabbit. Brain Res 305:323-330.

Marek GJ, McMaster SE, Gormezano I, Harvey JA (1984) The role of the accessory abducens nucleus in the rabbit nictitating membrane response. Brain Res 299:215-229.

Martina M, Gorfinkel Y, Halman S, Lowe JA, Periyalwar P, Schmidt CJ, Bergeron R (2004) Glycine transporter type 1 blockade changes NMDA receptor-mediated responses and LTP in hippocampal CA1 pyramidal cells by altering extracellular glycine levels. J Physiol 557:489-500.

McBride RL, Klemm WR (1968) Stereotaxic atlas of rabbit brain, based on the rapid method of photography of frozen, unstained sections. Comm Behav Biol 2 (Part A):179-215.

McCormick DA, Thompson RF (1984) Neuronal responses of the rabbit cerebellum during acquisition and performance of a classically conditioned nictitating membrane-eyelid response. J Neurosci 4:2811-2822.

McCormick DA, Lavond DG, Thompson RF (1982) Concomitant classical conditioning of the rabbit nictitating membrane and eyelid responses: correlations and implications. Physiol Behav 28:769-775.

McCormick DA, Lavond DG, Thompson RF (1983) Neuronal responses of the rabbit brainstem during performance of the classically conditioned nictitating membrane (NM)/eyelid response. Brain Res 271:73-88.

McDonald AJ, Pearson JC (1989) Coexistence of GABA and peptide immunoreactivity in non-pyramidal neurons of the basolateral amygdala. Neurosci Lett 100:53-58.

McNeal DW, Ge J, Herrick JL, Stilwell-Morecraft KS, Morecraft RJ (2008) Characterization of some morphological parameters of orbicularis oculi motor neurons in the monkey. Neuroscience 151:12-27.

Mettenleiter TC (2002) Herpesvirus assembly and egress. J Virol 76: 1537-1547.

Mettenleiter TC, Klupp BG, Granzow H (2006) Herpesvirus assembly: a tale of two membranes. Curr Opin Microbiol 9:423-429.

Molineux ML, Mehaffey WH, Tadayonnejad R, Anderson D, Tennent AF, Turner RW (2008) Ionic factors governing rebound burst phenotype in rat deep cerebellar neurons. J Neurophysiol 100:2684-2701.

Morcuende S, Delgado-Garcia JM, Ugolini G (2002) Neuronal premotor networks involved in eyelid responses: retrograde transneuronal tracing with rabies virus from the orbicularis oculi muscle in the rat. J Neurosci $22: 8808-8818$.

Mostofi A, Holtzman T, Grout AS, Yeo CH, Edgley SA (2010) Electrophysiological localization of eyeblink-related microzones in rabbit cerebellar cortex. J Neurosci 30:8920-8934.

Nowak AJ, Gormezano I (1990) Electrical stimulation of brainstem nuclei: elicitation, modification, and conditioning of the rabbit nictitating membrane response. Behav Neurosci 104:4-10.

Ottersen OP, Storm-Mathisen J (1984) Glutamate- and GABA-containing neurons in the mouse and rat brain, as demonstrated with a new immunocytochemical technique. J Comp Neurol 229:374-392.

Ottersen OP, Storm-Mathisen J, Somogyi P (1988) Colocalization of glycine-like and GABA-like immunoreactivities in Golgi cell terminals in the rat cerebellum: a postembedding light and electron microscopic study. Brain Res 450:342-353.

Perrett SP, Mauk MD (1995) Extinction of conditioned eyelid responses requires the anterior lobe of cerebellar cortex. J Neurosci 15:2074-2080.

Pijpers A, Voogd J, Ruigrok TJ (2005) Topography of olivo-cortico-nuclear modules in the intermediate cerebellum of the rat. J Comp Neurol 492:193-213.

Pugh JR, Raman IM (2006) Potentiation of mossy fiber EPSCs in the cerebellar nuclei by NMDA receptor activation followed by postinhibitory rebound current. Neuron 51:113-123.

Radpour S (1977) Organization of the facial nerve nucleus in the cat. Laryngoscope 87:557-574.

Ramnani N, Yeo CH (1996) Reversible inactivations of the cerebellum prevent the extinction of conditioned nictitating membrane responses in rabbits. J Physiol 495 (Pt 1):159-168.

Roche M, Commons KG, Peoples A, Valentino RJ (2003) Circuitry underlying regulation of the serotonergic system by swim stress. J Neurosci 23:970-977.

Roettger VR, Pearson JC, Goldfinger MD (1989) Identification of gammaaminobutyric acid-like immunoreactive neurons in the rat cuneate nucleus. Neurosci Lett 97:46-50.
Rubio ME, Juiz JM (2004) Differential distribution of synaptic endings containing glutamate, glycine, and GABA in the rat dorsal cochlear nucleus. J Comp Neurol 477:253-272.

Sanchez M, Sillitoe RV, Attwell PJ, Ivarsson M, Rahman S, Yeo CH, Hawkes R (2002) Compartmentation of the rabbit cerebellar cortex. J Comp Neurol 444:159-173.

Sánchez-Campusano R, Gruart A, Fernández-Mas R, gado-Garcia JM (2012) An agonist-antagonist cerebellar nuclear system controlling eyelid kinematics during motor learning. Front Neuroanat 6:8.

Schreurs BG, Sanchez-Andres JV, Alkon DL (1991) Learning-specific differences in Purkinje-cell dendrites of lobule HVI (Lobulus simplex): intracellular recording in a rabbit cerebellar slice. Brain Res 548: $18-22$.

Schreurs BG, Tomsic D, Gusev PA, Alkon DL (1997) Dendritic excitability microzones and occluded long-term depression after classical conditioning of the rabbit's nictitating membrane response. J Neurophysiol 77:86-92.

Schreurs BG, Gusev PA, Tomsic D, Alkon DL, Shi T (1998) Intracellular correlates of acquisition and long-term memory of classical conditioning in Purkinje cell dendrites in slices of rabbit cerebellar lobule HVI. J Neurosci 18:5498-5507.

Shaikh AG, Ghasia FF, Dickman JD, Angelaki DE (2005) Properties of cerebellar fastigial neurons during translation, rotation, and eye movements. J Neurophysiol 93:853-863.

Shek JW, Wen GY, Wisniewski HM (1986) Atlas of the rabbit brain and spinal chord. Basel: Krager.

Siebold C, Glonti L, Glasauer S, Büttner U (1997) Rostral fastigial nucleus activity in the alert monkey during three-dimensional passive head movements. J Neurophysiol 77:1432-1446.

Sillitoe RV, Marzban H, Larouche M, Zahedi S, Affanni J, Hawkes R (2005) Conservation of the architecture of the anterior lobe vermis of the cerebellum across mammalian species. Prog Brain Res 148:283-297.

Simat M, Parpan F, Fritschy JM (2007) Heterogeneity of glycinergic and gabaergic interneurons in the granule cell layer of mouse cerebellum. J Comp Neurol 500:71-83.

Smith BN, Banfield BW, Smeraski CA, Wilcox CL, Dudek FE, Enquist LW, Pickard GE (2000) Pseudorabies virus expressing enhanced green fluorescent protein: A tool for in vitro electrophysiological analysis of transsynaptically labeled neurons in identified central nervous system circuits. Proc Natl Acad Sci U S A 97:9264-9269.

Song CK, Enquist LW, Bartness TJ (2005) New developments in tracing neural circuits with herpesviruses. Virus Res 111:235-249.

Song G, Wang H, Xu H, Poon CS (2012) Kolliker-Fuse neurons send collateral projections to multiple hypoxia-activated and nonactivated structures in rat brainstem and spinal cord. Brain Struct Funct. doi:10.1007/s00429-012-0384-7.

Stanić D, Kuteeva E, Nylander I, Hökfelt T (2010) Characterization of CGRP protein expression in "satellite-like" cells and dendritic arbours of the mouse olfactory bulb. J Comp Neurol 518:770-784.

Steinmetz JE, Logue SF, Steinmetz SS (1992) Rabbit classically conditioned eyelid responses do not reappear after interpositus nucleus lesion and extensive post-lesion training. Behav Brain Res 51:103-114.

Sugihara I (2011) Compartmentalization of the deep cerebellar nuclei based on afferent projections and aldolase $\mathrm{C}$ expression. Cerebellum 10:449-463.

Sugihara I, Quy PN (2007) Identification of aldolase C compartments in the mouse cerebellar cortex by olivocerebellar labeling. J Comp Neurol 500:1076-1092.

Sugihara I, Shinoda Y (2007) Molecular, topographic, and functional organization of the cerebellar nuclei: analysis by three-dimensional mapping of the olivonuclear projection and aldolase C labeling. J Neurosci 27:9696-9710.

Sultan F, König T, Möck M, Thier P (2002) Quantitative organization of neurotransmitters in the deep cerebellar nuclei of the Lurcher mutant. J Comp Neurol 452:311-323.

Sun LW (2012) Transsynaptic tracing of conditioned eyeblink circuits in the mouse cerebellum. Neuroscience 203:122-134.

Takada M, Itoh K, Yasui Y, Mitani A, Nomura S, Mizuno N (1984) Distribution of premotor neurons for orbicularis oculi motoneurons in the cat, with particular reference to possible pathways for blink reflex. Neurosci Lett 50:251-255.

Teune TM, van der Burg J, van der Moer J, Voogd J, Ruigrok TJ (2000) 
Topography of cerebellar nuclear projections to the brain stem in the rat. Prog Brain Res 124:141-172.

Thompson RF, Steinmetz JE (2009) The role of the cerebellum in classical conditioning of discrete behavioral responses. Neuroscience 162:732-755.

Tolbert DL, Massopust LC, Murphy MG, Young PA (1976) The anatomical organization of the cerebello-olivary projection in the cat. J Comp Neurol 170:525-544.

Tomishima MJ, Smith GA, Enquist LW (2001) Sorting and transport of alpha herpesviruses in axons. Traffic 2:429-436.

Ugolini G (2011) Rabies virus as a transneuronal tracer of neuronal connections. Adv Virus Res 79:165-202.

Uusisaari M, Knöpfel T (2010) GlyT2+ neurons in the lateral cerebellar nucleus. Cerebellum 9:42-55.

Uusisaari M, Knöpfel T (2011) Functional classification of neurons in the mouse lateral cerebellar nuclei. Cerebellum 10:637-646.

Van Daele DJ, Cassell MD (2009) Multiple forebrain systems converge on motor neurons innervating the thyroarytenoid muscle. Neuroscience 162:501-524.

van Ham JJ, Yeo CH (1996a) The central distribution of primary afferents from the external eyelids, conjunctiva, and cornea in the rabbit, studied using WGA-HRP and B-HRP as transganglionic tracers. Exp Neurol 142:217-225.

van Ham JJ, Yeo CH (1996b) Trigeminal inputs to eyeblink motoneurons in the rabbit. Exp Neurol 142:244-257.

VanderWerf F, Aramideh M, Otto JA, Ongerboer de Visser BW (1998) Ret- rograde tracing studies of subdivisions of the orbicularis oculi muscle in the rhesus monkey. Exp Brain Res 121:433-441.

Villar-Cerviño V, Abalo XM, Villar-Cheda B, Meléndez-Ferro M, PérezCostas E, Holstein GR, Martinelli GP, Rodicio MC, Anadón R (2006) Presence of glutamate, glycine, and gamma-aminobutyric acid in the retina of the larval sea lamprey: comparative immunohistochemical study of classical neurotransmitters in larval and postmetamorphic retinas. J Comp Neurol 499:810-827.

Vogel RW, Amundson JC, Lindquist DH, Steinmetz JE (2009) Eyeblink conditioning during an interstimulus interval switch in rabbits (Oryctolagus cuniculus) using picrotoxin to disrupt cerebellar cortical input to the interpositus nucleus. Behav Neurosci 123:62-74.

Whealy ME, Robbins AK, Enquist LW (1988) Pseudorabies virus glycoprotein gIII is required for efficient virus growth in tissue culture. J Virol 62:2512-2515.

Wu XY, Zhu JX, Gao J, Owyang C, LiY (2005) Neurochemical phenotype of vagal afferent neurons activated to express C-FOS in response to luminal stimulation in the rat. Neuroscience 130:757-767.

Yeo CH, Hardiman MJ, Glickstein M (1985) Classical conditioning of the nictitating membrane response of the rabbit. III. Connections of cerebellar lobule HVI. Exp Brain Res 60:114-126.

Yokota T, Koyama N, Nishikawa Y, Nishikawa N, Nishida Y, Hasegawa A, Fujino Y (1991) Trigeminal nociceptive neurons in the subnucleus reticularis ventralis. I. Response properties and afferent connections. Neurosci Res 11:1-17. 